\title{
EL APÉNDICE SEGUNDO DEL DICCIONARIO ENCICLOPÉDICO HISPANO-AMERICANO DE LITERATURA, CIENCIAS Y ARTES (1907-1910) DE MONTANER Y SIMÓN
}

\author{
DAVID PRIETO GARCÍA-SECO \\ Universidad de Murcia
}

\section{EL DICCIONARIO ENCICLOPÉDICO HISPANO-AMERICANO (1887-1898)}

Componen el cuerpo del Diccionario enciclopédico hispano-americano (1887-1898; DEHA) veintitrés gruesos tomos en veinticuatro volúmenes ${ }^{1}$. Al igual que otras obras de la época, el DEHA se fue publicando por entregas. Generalmente, el suscriptor recibía a la semana un cuaderno de cuarenta páginas. En la elaboración de esta obra decimonónica participó un buen número de colaboradores. En el primer tomo encontramos una «Lista de los autores encargados de la redacción de este diccionario», donde se hallan, entre otros, Augusto Arcimis (astronomía, meteorología y cronología), Gumersindo Azcárate (sociología y política), José Echegaray (magnetismo y electricidad), Francisco Giner de los Ríos (estética), Urbano González Serrano (filosofía), José Ramón Mélida (mitologías, arqueología oriental y clásica, indumentaria, panoplia, heráldica y artes industriales extranjeras de las edades media y moderna), Marcelino Menéndez

${ }^{1}$ La presente introducción, en la que pretendemos señalar las características principales del DEHA con el objeto de que posteriormente se comprendan cabalmente las aportaciones de su Apéndice segundo, supone un compendio de lo expuesto en D. Prieto García-Seco «El Diccionario enciclopédico hispano-americano de literatura, ciencias y artes (1887-1910) de la editorial Montaner y Simón», Boletín de la Real Academia Española, LXXXVII, 2007, págs. 97-121.

AnMal, XXXIX, 2016-2017, págs. 203-246 
Pelayo (obras maestras de la Literatura española), Francisco Pi y Margall (filosofía del derecho) o José María Sbarbi (lexicografía, gramática y música).

Aunque no se indica en la portada quién dirigió el DEHA, sabemos que inicialmente se encargó de la dirección Eduardo Benot, si bien esta tan solo duró cuatro meses, según confesó él mismo en una carta recogida en el Gran diccionario de la lengua castellana de Aniceto de Pagés². La dirección definitiva, no obstante, la ostentó este último, quien, además, se ocupó de la tarea de recopilar textos, tanto de fuentes primarias como de fuentes secundarias, con los que avalar el uso de algunas de las voces registradas ${ }^{3}$.

En cuanto a las voces de lengua registradas en el DEHA, la obra de Montaner y Simón se hizo heredera de una de las prácticas más antiguas de la disciplina lexicográfica al partir para conformar la suya de la macroestructura, y de las microestructuras, de la edición de 1884 del diccionario usual de la Real Academia Española. Sobre esta base se añadieron diversos materiales léxicos (voces, acepciones, autoridades, etc.) obtenidos a partir de varias fuentes.

El DEHA fue uno de los pocos diccionarios que retomaron la práctica de la cita textual, cuya relevancia se pone de manifiesto en las afirmaciones que se hacen en el artículo diccionario del propio DEHA, redactado probablemente por Aniceto de Pagés, encargado, como se ha dicho, de recolectar las autoridades:

Las autoridades o ejemplos sobre la manera de usar las palabras por los escritores insignes de la lengua forman una muy importantísima parte de los diccionarios, parte que generalmente se omite, se descuida muy a menudo y que pocas veces es atendida con el esmero que merece. Un diccionario sin ejemplos parece que no tiene más autoridad que la autoridad de su autor. La Academia Francesa siempre ha reclamado el derecho de hacer ella misma los ejemplos. Con este motivo decía Voltaire: «parece que se han hecho una ley del no citar», y añadía: «un diccionario sin citas es un esqueleto». La primera edición del Diccionario hecho por la Academia Española en 1726 tiene autoridades. En las ediciones siguientes se suprimieron. Las autoridades deben colocarse debajo de la acepción que ilustren, sistema que es el más útil y usual. En los idiomas que poseen una literatura rica pueden colocarse cronológicamente, como propuso la Sociedad Filológica [de Inglaterra]. Cada autoridad

2 A. de Pagés, Gran diccionario de la lengua castellana, autorizado con ejemplos de buenos escritores antiguos y modernos, Madrid, I, 1902, pág. X.

3 Véase D. Prieto García-Seco, «El Diccionario enciclopédico hispano-americano de literatura, ciencias y artes (1887-1898) de la editorial Montaner y Simón», pág. 100 y, especialmente, nota 9. Para obtener más datos sobre la dirección del DEHA, consúltese P. Pardo Herrero, El Diccionario enciclopédico hispano-americano de Montaner y Simón: a propósito del léxico de la ciencia y de la técnica, Servei de Publicacions de la Universitat Autònoma de Barcelona, 2013, págs. 36-39 (ed. electrónica: <http://www.tdx.cat/handle/10803/96707>; consulta: 15/09/2015) y P. Pardo Herrero, «El primer director del Diccionario enciclopédico Hispano-Americano de Montaner y Simón [Eduardo Benot]», Revista de Lexicogafía, XIX, 2013, págs. 71-86. 
debe dejar completo el sentido de la frase en que se emplea la palabra que se trata de ilustrar, y no ser un fragmento de una sentencia. Si es posible ha de ser instructiva e interesante, pero no por esto debe ser demasiado larga. El mérito de un diccionario y la riqueza de su vocabulario dependen, en gran parte, del cuidado y la extensión con que se hayan buscado las autoridades o ejemplos, y únicamente será completo en este respecto cuando la colección de las autoridades se haya hecho en toda la literatura del lenguaje ${ }^{4}$.

A nuestro juicio, la aportación de algunas autoridades en determinadas entradas constituye la característica más notable de esta colosal obra ${ }^{5}$. No obstante, resulta necesario indicar que la cita de textos en el DEHA ni es sistemática ni tan abundante como quisiéramos. De acuerdo con nuestros cálculos, por término medio aparecen 3,6 autoridades por página ${ }^{6}$. La cita consiste en un pequeño texto seguido del nombre del autor o, a veces, del título de la obra, sin referencia a páginas ni a ediciones empleadas. A pesar de que no se indicó la fuente lexicográfica, muchos de los textos habían sido tomados del Diccionario de autoridades (1726-1739): algo más del $40 \%$ de los textos citados en el DEHA procedía del primer diccionario académico ${ }^{7}$. Otro repertorio lexicográfico del que se obtuvieron textos fue el Diccionario de construcción y régimen de la lengua castellana (1886-1893) de Cuervo ${ }^{8}$. Dada la fecha de publicación de los dos tomos del DCR, los colaboradores del DEHA únicamente pudieron servirse del primero, pero no del segundo, puesto que los tomos de las letras C y D del DEHA vieron la luz entre los años 1888 y 1890.

Además de valerse de dichas obras lexicográficas, el DEHA también acudió a fuentes primarias y de ellas obtuvieron nuevas voces y acepciones, y sus textos

${ }^{4}$ DEHA, vI, 1890, pág. 566b.

${ }^{5}$ Cf. D. Prieto García-Seco, «El Diccionario enciclopédico hispano-americano de literatura, ciencias y artes (1887-1898) de la editorial Montaner y Simón: reflexiones en torno a su nomenclatura y sus fuentes textuales», en J. M. García Martín (dir.) y V. Gaviño Rodríguez (eds.), Las ideas y realidades lingüísticas en los siglos XVIII y XIX, Servicio de Publicaciones de la Universidad de Cádiz, 2009, págs. 535-549; y D. Prieto García-Seco, «Las autoridades del Diccionario enciclopédico hispano-americano de literatura, ciencias y artes (1887-1898) de la editorial Montaner y Simón», RILCE, Revista de Filología Hispánica, 26, 2, 2010, págs. 383-401.

6 «El Diccionario enciclopédico hispano-americano de literatura, ciencias y artes (1887-1898) de la editorial Montaner y Simón», 2007, pág. 106, señalamos que para obtener tal cifra llevamos a cabo un cómputo de los textos citados entre las páginas 201 y 300, ambas incluidas, de los 23 tomos del cuerpo del DEHA (en el caso del t. v, vol. 2, se ha tenido en cuenta de la pág. 1201 a la 1300), lo que aproximadamente constituye el $10 \%$ de la obra.

7 Real Academia Española, Diccionario de la lengua castellana, en que se explica el verdadero sentido de las voces, su naturaleza y calidad, con las phrases o modos de hablar, los proverbios o refranes y otras cosas convenientes al uso de la lengua, Madrid, 1726-1739, 6 vols.

8 R. J. Cuervo, Diccionario de construcción y régimen de la lengua castellana, I [A y B], 1886, y II [C y D], 1893, París. 
correspondientes. Con este segundo procedimiento se ejercía el oficio de lexicógrafo del mejor modo posible, registrando voces y acepciones de modo inductivo, a partir de lo que se encontraban en una base documental. A ella habremos de referiremos más adelante $(\S 3.2)$.

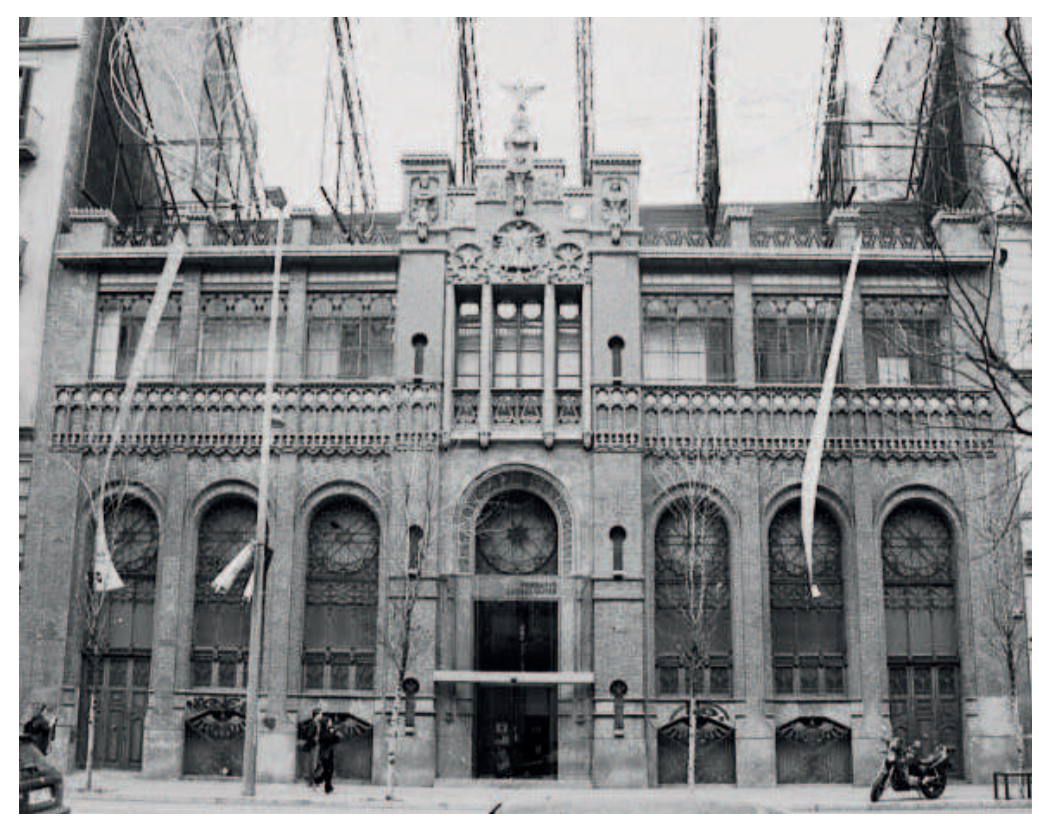

Edificio modernista de la antigua editorial Montaner y Simón

(C/ Aragón - Barcelona)

\section{EL APÉNDICE SEGUNDO (1907-1910) DEL DICCIONARIO ENCICLOPÉDICO HISPANO- -AMERICANO}

La primera etapa del DEHA concluyó a finales del siglo XIX con la publicación de un apéndice, que correspondía a los tomos XXIV (1898) y XXV (1899), donde fundamentalmente se recogieron palabras con marcas técnicas o marcas relativas a algún ámbito del conocimiento o a diversas actividades humanas9. Ocho años más tarde, en 1907, salió de las prensas el primero de los tres tomos del

${ }^{9}$ Cf. acordonador (Ind.), acrosaurio (Paleont.), actinanto (Bot.), aflebia (Zool.), agnosticismo (Fil.), amenílico (Quím.), artrófilo (Bot.), baierina (Miner.), balastaje (Ferrocarr.), ballesterosita (Min.), buchú (Farm.), calvanadita (Min.), candle (Fís.), devitrificación (Geol.), dioxidimetilanilina (Quim.), esfenandra (Bot.), faujasita (Min.), fiambrera (Art. y Of.), flujo (Magn. y Electr.), fonogenógrafo (Fís.), etc. En su estudio P. Pardo Herrero, op. cit., pág. 159, viene a confirmar la abrumadora recepción de voces con marcas técnicas a la que nos referimos: «En el primer apéndice, siguiendo los datos ofrecidos por la revisión del $5 \%$ [del $D E H A]$, apenas un $0,6 \%$, tres entradas, no tiene marca de especialidad (embotellado 'operación de embotellar', 
Apéndice segundo (A2DEHA); los dos siguientes lo harían en 1908 y 1910. Resulta necesario estudiar de modo separado estos tres tomos, puesto que, a pesar de tratarse de un apéndice, presentan diferencias que los apartan significativamente del cuerpo de la obra. El propósito de este trabajo es, precisamente, mostrar las características generales del A2DEHA y estudiar esas diferencias.

De modo contrario a lo que sucedía en todos los volúmenes del cuerpo del DEHA, en este nuevo apéndice no existe una nómina de colaboradores; sin embargo, se manifiesta a quién se confió la dirección de esta empresa: en la portada se expresa que este apéndice fue «redactado por distinguidos profesores y publicistas de España y América, bajo la dirección de Pelayo Vizuete». Según la Enciclopedia Espasa ${ }^{10}$, Pelayo Vizuete Picón «dirigió el Diccionario enciclopédico de Montaner y Simón durante más de doce años; redactó el 2 . Apéndice y multitud de artículos que figuran en dicha obra»"1. Este no sería el único trabajo lexicográfico que realizó para Montaner y Simón; unos años más tarde fue redactor-jefe del Diccionario tecnológico hispano-americano (1926-1930), obra incompleta, proyectada por Leonardo Gómez Quevedo, de la que tan solo disponemos de seis cuadernos, que comprenden hasta la palabra arquibuteo $^{12}$. Como veremos a continuación la dirección de Pelayo Vizuete supuso, sin lugar a dudas, un importante cambio de rumbo en este apéndice.

odontología 'tratado de las enfermedades dentarias' y *saludador 'falso hechicero'); es decir, que un $99,4 \%$ de las entradas está marcado».

${ }^{10}$ Enciclopedia universal ilustrada europeo-americana [...], Espasa-Calpe, Madrid, LXIX, 1929.

${ }^{11}$ La entrada biográfica que el A2DEHA (1910) dedica a Vizuete Picón señala lo siguiente sobre su labor de dirección y redacción de artículos: «Desde la última fecha indicada [1904] reside en la capital de Cataluña, en donde, ayudado por su esposa, mujer de encantadora sencillez, de envidiable cultura y superior talento, se dedica intensamente a trabajos científicos de importancia, entre ellos la publicación del presente APÉNDICE. [...] Ha dirigido la publicación de este APÉNDICE, y para él ha redactado millares de artículos sobre diversas materias, principalmente sobre Literaturas clásicas y modernas, Ciencias naturales, Filología, Medicina y Derecho».

${ }_{12}$ Cf. P. Álvarez de Miranda, Los diccionarios del español moderno, Trea, Gijón, 2011, págs. 178-179, y C. Garriga Escribano, «Acercamiento lexicográfico al Diccionario tecnológico hispano-americano», en M. P. García Gómez (ed.), Lexicografía especializada: nuevas propuestas, (Anexo de Revista de Lexicografía, 25), Universidade da Coruña-Servizo de Publicacións, 2014, págs. 29-46. 


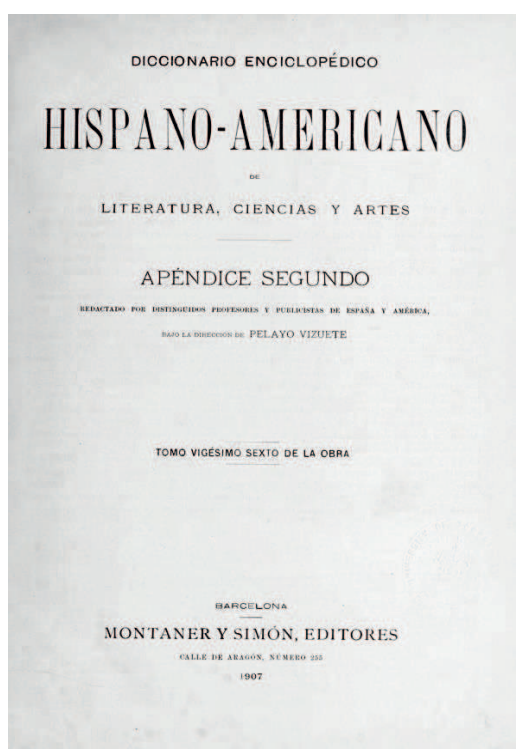

Portada del tomo xxvI del Diccionario enciclopédico hispano-americano (1907) Apéndice segundo

Huelga decir que la condición de apéndice llevaba consigo la relación y dependencia con los tomos hasta entonces publicados; así, lo primero que se señala en las Advertencias del A2DEHA es que el asterisco situado a la izquierda de la palabra-lema de algunos artículos significa que

[...] estos han sido ya tratados en el cuerpo de la obra o que dicha palabra se halla incluida en nuestro DICCIONARIO con sus principales acepciones: se trata, pues, en este segundo APÉNDICE, de completar los mentados artículos o de añadir a las ya dadas en los lugares respectivos nuevas acepciones de los indicados términos. Los artículos que no llevan asterisco son enteramente nuevos ${ }^{13}$.

En esta ocasión la macroestructura del A2DEHA no podía ser la del DRAE vigente, la edición de 1899; de haber sido así, prácticamente todas las voces inventariadas habrían coincidido con el cuerpo del DEHA (1887-1898). Ello no significa, evidentemente, que se renunciara a utilizar ciertos materiales léxicos que podía proporcionar dicha edición; de hecho, se incluyeron en el $A 2 D E H A$ voces y acepciones registradas por primera en esta edición académica $^{14}$. En cualquier caso, las adiciones del DRAE de 1899 sobre la edición de

${ }^{13}$ A2DEHA, XXVI, 1907, pág. [4]. En adelante reproducimos este asterisco cuando corresponda.

${ }_{14}$ Cf. esborregar, *escabechado, escavanar, escocedura, fabada, fabliella, faceruelo, factoril, fajinada, famular, fardero, gabuzo, galayo, quillotra, quillotrador, quillotranza, etc. Ha de precisarse, no obstante, que no siempre se limitaron a copiar al pie de la letra aquellos artículos; en ocasiones modificaron algún aspecto, como, por ejemplo, las definiciones. El artículo faraónico figura en el DRAE de 1899 con la acepción «perteneciente o relativo a los faraones», y en el A2DEHA: "perteneciente o relativo a los faraones, o a la época de estos 
1884 no suponían un caudal léxico tan abundante como para constituir por sí solas una nueva base para el $A 2 D E H A$. Téngase en cuenta que estamos hablando de más de 3700 páginas. Importa conocer, en consecuencia, qué tipo de voces componen la macroestructura de este apéndice y, en la medida de lo posible, de qué modo se cosecharon.

En primer lugar, debemos decir que dejamos al margen las entradas puramente enciclopédicas; nuestro estudio, por tanto, se centra en las voces de lengua, es decir, en el diccionario de lengua que, bajo el orden del abecé, se combina con aquellas entradas (antropónimos, topónimos, etc.).

Llama la atención el abundante registro de términos con marcación técnica o con marcas atinentes a ciertos ámbitos del conocimiento o de las actividades humanas. Sobre la importante presencia de estas voces ha de acudirse al trabajo de Pardo Herrero ${ }^{15}$, quien, de acuerdo con el estudio de un $10 \%$ del A2DEHA, afirma que en este apéndice «un $37 \%$ son voces no marcadas con abreviaturas de especialidad y un $63 \%$ son voces que tienen marca de especialidad o enciclopédica» ${ }^{16}$. Las que siguen son algunas de estas últimas voces:

aal (Bot.), abaritonado (Mús.), abdera (Zool.), abimelec (Filol.), abismo (Blas.), aborregado (Geol.), abraun (Mitol.), abraquiocéfalo (Terat.), abrina (Microbiol.), acalefos (Paleont.), albificación (Tecn.), algospasmo (Med.), almarvatar (Carp.), almarvate (Carp.), altimétrico (Mat.), animalculovismo (Embriol.), animalización (Fisiol.), astrostática (Cosm.), brecmático (Anat.), breina (Bot.), breviario (Imp.), coindicar (Terap.), desembarcador (Mar.), desembocadura (Mil.), desempiolar (Cetr.), diazotipia (Fotogr.), dibencilcarbonato (Quím.), dicimbio (Zool.), dicirtoma (Zool.), discrásico (Patol.), *discreción (Filos.), disloquia (Obst.), reotropismo (Biol.), *reponer (For.), retenida (Mar.), *retiración (Impr.), *retroceso (Mec.), *revoltón (Arq.), ribequita (Miner.), *voltaje (Fís.), voltejeo (Mar.), vulcanismo (Geol), vulcanista (Geol), zafrero (Miner.).

Otra de las grandes aportaciones léxicas es la de los adjetivos gentilicios. No solo se dio entrada a gentilicios pertenecientes a grandes poblaciones, ciudades, etc., sino también a los relativos a pequeñas localidades o pueblos. En la tabla siguiente recogemos algunos de estos gentilicios con sus definiciones correspondientes. Téngase en cuenta que no reproducimos ni la indicación gramatical «U.t.c.s.», que normalmente sigue a tales definiciones, ni la segunda

soberanos egipcios. Monumento FARAÓNICO». Vemos, por tanto, que no solo hay una ampliación del enunciado definidor, sino que existe la adición de un ejemplo inventado. No se incluyeron en el $A 2 D E H A$, sin embargo, otras voces que se registraban por primera vez en el $D R A E$, tales como ametralladora, concertista, conceto, conjuntivitis, decuplicar, escafoides, falangiano, faringitis, farmacológico, realización, etc. P. Pardo Herrero, op. cit., págs. 405-419, ofrece más datos sobre la explotación del DRAE (1899) en relación con los términos «marcados con abreviatura de especialidad».

15 P. Pardo Herrero, loc. cit., págs. 160-162.

16 P. Pardo Herrero, loc. cit., pág. 160. 
definición que se recoge sistemáticamente en los artículos de gentilicios, aquella que denota pertenencia o relación casi siempre mediante la pauta $<$ Perteneciente o relativo a dicha población española/italiana, etc. $>17$.

\begin{tabular}{|c|c|}
\hline GENTILICIO & DEFINICIÓN \\
\hline *aguileño & «Natural de Águilas (Murcia)» \\
\hline aguimense & «Natural de Aguimes (Canarias)» \\
\hline alagonero & «Natural de Alagón» (Zaragoza)» \\
\hline alayorense & «Natural de Alayor (Islas Baleares)» \\
\hline baracaldés & «Natural de Baracaldo (Vizcaya)» \\
\hline baracoense & «Natural de Baracoa (Isla de Cuba)» \\
\hline barajeño & «Natural de Barajas de Melo (Cuenca)» \\
\hline barbarense & «Natural de Barbará (Tarragona)» \\
\hline barcalés & «Natural de Negreira (Coruña)» \\
\hline barcarrotense & «BARCARROTEÑO, ÑA» \\
\hline barcarroteño & «Natural de Barcarrota (Badajoz)» \\
\hline barrajeño & «Natural de Barrax (Albacete)» \\
\hline barranqueño & «Natural de San Esteban del Val (Ávila)» \\
\hline barreño & «Natural de Bienvenida (Badajoz)» \\
\hline barroso & «Natural de Barro (Pontevedra)» \\
\hline boñarense & «Natural de Boñar (León)» \\
\hline coinense & «Natural de Coín (Málaga)» \\
\hline coineño & «COINENSE» \\
\hline rianjeiro & «Natural de Rianjo (Coruña)» \\
\hline riañés & «Natural de Riaño (León)» \\
\hline ribadaviense & «Natural de Ribadavia (Orense)» \\
\hline ribadedense & «Natural de Ribadedeva (Oviedo)» \\
\hline ribadense & «Natural de Ribadeo (Lugo)» \\
\hline ribadesellense & «Natural de Ribadesella (Oviedo)» \\
\hline ribarrojano & «Natural de Ribarroja (Tarragona)» \\
\hline ribarrojeño & «Natural de Ribarroja (Valencia)» \\
\hline ribesalbense & «Natural de Ribesalbes (Castellón)» \\
\hline riclano & «Natural de Ricla (Zaragoza)» \\
\hline ricoteño & «Natural de Ricote (Murcia)» \\
\hline
\end{tabular}

${ }_{17}$ Decimos «casi siempre» porque también encontramos otras redacciones en virtud del tipo de población, como «Perteneciente o relativo a este cantón suizo» (s. v. vodense). 


\begin{tabular}{|l|l|}
\hline turcitano & «Natural de Martos (Jaén)» \\
\hline turégano & «Natural de Turégano (Segovia)» \\
\hline turiasonense & «Natural de Tarazona (Zaragoza)» \\
\hline tursiano & «Natural de Turín» \\
\hline vodense & «Natural de Vaud» \\
\hline yunquerano & «Natural de Yunquera (Málaga)» \\
\hline zafarrayero & «Natural de Zafarraya (Granada)» \\
\hline
\end{tabular}

Algunos gentilicios recogidos en el A2DEHA (1907-1910)

Las voces con marca diatópica también tienen un protagonismo importante en el A2DEHA. Aunque encontramos marcas referidas a distintas provincias de la Península - a una de ellas nos referiremos a continuación-, predominan los términos con la marca Amer. o Amér. (abocastro, achura, aindiado, ajeniar, alambrado, asorocharse, ayrampo, bagrero, bagual, boleadoras, borlarse, botadero, cachirla, cocacho, etc.). Además, debe saberse que, cuando, gracias a los materiales manejados, estuvo en la mano de los redactores del A2DEHA acotar el ámbito geográfico de una voz americana, emplearon, tras la marca en cuestión, sintagmas especificadores como los que siguen: «Amer. (de Colomb.)» (s. v. atramojar), «Amer. (Usado en el Cauca de Colombia)» (s. v. bimbo), «Amer. (del Cauca)» (s. v. bolero), «Amer. (propio del Cauca, de Colombia)» (s. v. cagüinga), «Amer. (del Perú)» (s. v. disfuerzo), «Amer. (de las Antillas)» (s. v. grigri), «Amer. (de Cuba)» (s. v. guizazo), «Amér. (de Honduras)» (s. v. hueste y huestear), «Amer. (de Venezuela)» (s. v. *imbornal), «Amer. (de Chile)» (s. v. leso), «Amér. (de la Argentina)» (s. v. *planchar), «Amér. (de la Argent.)» (s. v. suri), «Amer. (de Venezuela)» (s. v. topocho), «Amer. (de Venezuela)» (s. v. tucuso), «Amer. (de la Argentina y de Chile)» (s. v. vidalita), «Amer. (de la Argent.)» (s. v. vincha), etc. ${ }^{18}$.

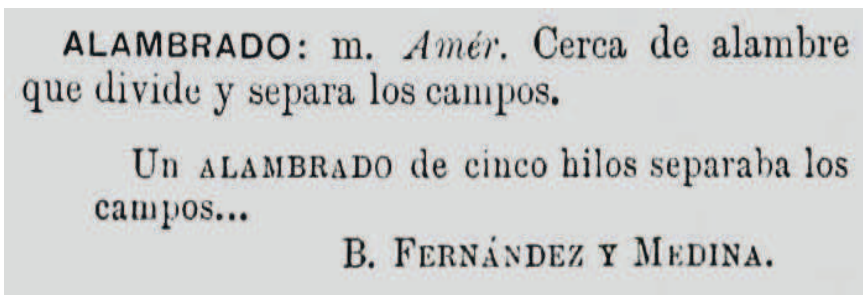

Art. alambrado del A2DEHA (1907)

${ }^{18} \mathrm{Al}$ respecto debe consultarse P. Pardo Herrero y C. Garriga Escribano, «El Diccionario enciclopédico hispano-americano: notas sobre la autoría y el tratamiento del español de América», en A. Nomdedeu Rull et alii (coords.), Avances en lexicografía hispánica, I, Universitat Rovira i Virgili, Tarragona, 2012, págs. 455-468; y, fundamentalmente, P. Pardo Herrero, op. cit., § 2.4. 
En relación con el ámbito peninsular, una de las marcas diatópicas de mayor aparición es «prov. Sant.» (= [término] provincial de Santander). Se trata de voces que se autorizan fundamentalmente con textos de José María de Pereda (cf. porrada, porredana, quima o recancaneado), de manera que cabe suponer que el lugar de nacimiento del autor determinó la aparición de aquella marca, como sucede con la voz esborregar, con idéntica marca y con un texto de Menéndez Pelayo. El predominio de la marca «prov. Sant.» es algo que no ha de extrañar, habida cuenta de que Pereda es uno de los autores más citados en el A2DEHA ( $\S 3.1 .2$ y 3.2).

Merecen también una mención especial las creaciones léxicas ocasionales ${ }^{19}$. $\mathrm{Su}$ recogida fue realmente generosa en el apéndice que estudiamos, lo que sin duda recuerda la actitud que manifestaron los primeros académicos en el Diccionario de autoridades, donde la cosecha de este tipo de voces fue también muy abundante ${ }^{20}$. En alguna rara ocasión estas voces reciben en el A2DEHA la marca «fest.» (escriborreteador, sastricida, sascripedante, tutujuleque, etc.), con la que se da cuenta de que estamos ante términos no pertenecientes a la lengua general ${ }^{21}$. Sin embargo, lamentablemente, lo habitual es que estas voces carezcan de marca alguna que indique su naturaleza. A continuación, citamos algunos de estos ocasionalismos, seguidos entre paréntesis, del autor o de la obra de que se obtuvieron:

ablucionarse (Castro y Serrano), abortona (La pícara Justina), acemilado (P. Isla), alfileresco (Cervantes), amacigado (Lope de Vega), angarillado (Tirso de Molina), badulaquero (Eugenio de Salazar), balconero (Tirso de molina), barbibermejo (Tirso de Molina), barbimoreno (Tirso de Molina), barbitonto (Lope de Vega), bárrelotodo [sic] (Juan del Espino), bayetuno (Cervantes), boquinecio (Lope de Vega), bracicaído (Ruiz del Alarcón), burrihombre (La pícara Justina), buscacomadres (Tirso de Molina), buscayernos (Lope de Vega), cabizcubierto (Eugenio

19 Sobre los rasgos de los ocasionalismos, puede consultarse D. Prieto García-Seco, «La creación léxica ocasional en la obra de Tirso de Molina», Boletín de la Real Academia Española, LXXXIV, 2009, págs. 49-54.

${ }^{20}$ Sobre la inclusión de voces calificadas de «jocosas», «inventadas» o «voluntarias», acúdase a los trabajos de S. Rushtaller, «Voces "inventadas" y "voluntarias” en el Diccionario de autoridades. Su caracterización en la microestructura», en J. Prado Aragonés y M. V. Galloso Camacho (eds.), Diccionario, léxico y cultura, Servicio de Publicaciones de la Universidad de Huelva, 2004, págs. 175-187; y «Voces "inventadas" y "voluntarias" en la macroestructura del Diccionario de autoridades», en J. J. de Bustos Tovar y J. L. Girón Alconchel (eds.), Actas del VI Congreso Internacional de Historia de la Lengua Española. Madrid, 29 de septiembre-3 de octubre 2003, II, Arco/Libros, Madrid, 2006, págs. 1673-1682. A propósito de los ocasionalismos procedentes de La pícara Justina recogidos en Autoridades, puede consultarse D. Prieto García-Seco, «La pícara Justina en el Diccionario de autoridades», en J. M. García Martín (dir.) y F. J. de Cos Ruiz y M. Franco Figueroa (coords.), Actas del IX Congreso Internacional de Historia de la Lengua Española (Cádiz, 2012), II, Iberoamericana/Vervuert, Madrid, 2015, págs. 1604-1610.

${ }^{21}$ Además de dicha marca, estas voces reciben la marca «fam.», a nuestro juicio inadecuadamente, puesto que en puridad no cabe adscribir tales voces al registro familiar. 
de Salazar), cachofotas (L. F. de Moratín), calderesco (Vicente Espinel), castañil (Bretón de los Herreros), cochizarse (Tirso de Molina), coliholgado (La picara Justina), dentipostizo (Pedro de Quirós), desdeñante (Tirso de Molina), desdoncellar (Tirso de Molina), desencambar (Pereda), desesperadizo (Ribera), desfantasmador (La pícara Justina), deshojaldrado (Tirso de Molina), deshombrecerse (La pícara Justina), deshonramalos (Alonso de Ledesma), desombrerarse (Calderón), diablismo (Juan del Espino), diaboluno (Juan Montalvo), diluviada (E. Pardo Bazán), dueñesco (Cervantes), dueñez (Calderón), enduendar (Tirso de Molina), engullefisgas (La pícara Justina), escriborreteador (L. F. de Moratín), escurrajas (L. Maldonado), excusapecados (Fr. Juan de Pineda), hembrilatina (Quevedo), mimógrafo (Lope de Vega), parvulista (E. Pardo Bazán; $\S$ 4.2), pasatarde (Lope de Vega), pasionalidad (E. Pardo Bazán), pastelista (E. Pardo Bazán), pastelizar (Tirso de Molina), pitonicida (Lope de Vega), poeticida (Lope de Vega), pontazguear (Juan Montalvo), sastril (Tirso de Molina), sastripedante (Lope de Vega), sastrizar (Tirso de Molina), satiricabro (Lope de Vega), sotasacristán (Cervantes), sotasacristanil (Cervantes), tutujuleque (P. Isla).

Tratados los grupos léxicos anteriores, en el siguiente apartado nos ocuparemos de las fuentes lexicográficas y textuales a las que recurrió el A2DEHA. Trataremos de mostrar que en gran medida merced a estas fuentes los redactores del Apéndice segundo lograron conformar el grueso de la macroestructura del diccionario de lengua, además de dotar de nuevas acepciones a entradas que previamente habían sido registradas en el cuerpo del DEHA.

\section{FUENTES LEXICOGRÁFICAS Y TEXTUALES DEL A2DEHA}

Se ha dicho que la dirección de Pelayo Vizuete trajo consigo no pocas novedades en la redacción del A2DEHA. Uno de los cambios más importantes se encuentra en las fuentes lexicográficas y textuales que se manejaron. Atenderemos, en primer lugar, a los diccionarios con citas textuales de que disponían los redactores del Apéndice segundo y observaremos a qué obras recurrieron y de qué modo lo hicieron. Posteriormente, no referiremos a las fuentes primarias; veremos entonces los textos que se emplearon para la composición del A2DEHA. Para llevar a cabo este estudio hemos tenido en cuenta 780 páginas de este apéndice ( $21 \%$ del total), concretamente, las primeras veinte páginas de cada centena de sus tres volúmenes (1-20, 101-120, 201-220, 301-320, etc.). Además, ha de saberse que en tales páginas hay un total de 994 artículos en los que se aduce al menos un texto, que suman un total de 1158 citas textuales. 


\subsection{Fuentes lexicográficas}

Lo primero que debemos indicar es que el número de textos que se citan por página en el A2DEHA se redujo en relación con el DEHA: mientras que en el cuerpo de la obra se citaban, como queda dicho, algo más de tres textos por página, ahora, en este nuevo apéndice, la media nos indica que tan solo se ofrece uno y medio por página ${ }^{22}$.

En cuanto a la procedencia de los textos, se ha dicho $(\S 1)$ que, si bien el cuerpo del DEHA hizo acopio de numerosas citas de primera mano, presentaba una gran cantidad de textos procedentes de diversos repertorios, entre los que destacaba el Diccionario de autoridades. Ha de subrayarse que tanto en el cuerpo del DEHA como en el apéndice que nos ocupa el manejo de fuentes secundarias o lexicográficas no tenía como único propósito la provisión de textos para los artículos preestablecidos, es decir, los que se tomaron, fundamentalmente, del DRAE de 1884 —en el caso del DEHA-y del DRAE de 1899 —en el caso del A2DEHA-, sino que la utilización de fuentes lexicográficas también supuso, obviamente, un incremento del lemario, puesto que los diccionarios utilizados recogían voces y acepciones que o bien no se incluían en dichas ediciones académicas, o bien se habían suprimido en ediciones precedentes.

Como sabemos, algo más del $40 \%$ de los textos citados en el cuerpo del DEHA procedían del Diccionario de autoridades. En el Apéndice segundo, por el contrario, se puede afirmar que no recurrieron ni a la primera edición de Autoridades ni a su segunda edición (1770) para cosechar voces y/o citas textuales ${ }^{23}$. Hemos cotejado las 1158 citas textuales de los 994 artículos mencionados con las citas aducidas en los artículos correspondientes de las dos ediciones del Diccionario de autoridades y tan solo hemos encontrado algunas coincidencias en ciertas citas. La siguiente tabla recoge los artículos -0 los fragmentos de los artículos - donde detectamos estas coincidencias. Debe indicarse que el único artículo que, en la columna de la izquierda, pertenece a la edición de Autoridades de 1770 es broncería.

22 Para obtener esta media se han realizado los dos siguientes cálculos. Por un lado, de igual modo que se hizo con las autoridades presentes en los 23 tomos del $D E H A$ (véase la nota 6), para el A2DEHA se han contado las citas textuales comprendidas entre las páginas 201 y 300 de cada uno de sus tres volúmenes. El resultado de este primer cálculo ha sido el siguiente: t. XXVI, 141 textos; t. XXVII, 141 textos; t. XXVIII, 203 textos. La media, por tanto, es de 1,6 textos por página. Por otro lado, en el segundo cálculo se han tenido en cuenta las 780 páginas consideradas en este estudio. Habida cuenta de que en estas páginas se recogen 1158 citas, la media es de 1,5 textos por página. Como se puede comprobar, los resultados obtenidos en ambos cálculos son semejantes, de manera que, extrapolando tales resultados al conjunto del Apéndice segundo, cabe conjeturar que esta media no sufrirá variaciones significativas.

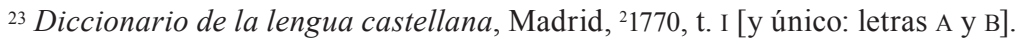




\begin{tabular}{|c|c|}
\hline Autoridades (1726-1739 y 1770) & A2DEHA (1907-1910) \\
\hline $\begin{array}{l}\text { ACABRONADO, DA. adj. Equivale a libre, des- } \\
\text { collado y estrellero, a imitación del cabrón, } \\
\text { o macho de cabrío, que siempre trahe el } \\
\text { rostro engreído, y mirando a lo alto. Es voz } \\
\text { voluntaria, y que usó Espinel en la vida } \\
\text { del Escudero Obregrón. Lat. Hircinum in } \\
\text { morem gerens vultum. Espin. Escud. sol. } \\
\text { 87. Los ojos aunque no pequeños cerrados } \\
\text { siempre que hablaba como si con los ojos } \\
\text { se oyera, y todo el rostro acabronado: } \\
\text { quiero decir libre, alto y desvergonzado. }\end{array}$ & $\begin{array}{l}\text { *ACABRONADO, DA: adj. Desvergonzado, } \\
\text { insolente. } \\
\text { Los ojos, aunque no pequeños, } \\
\text { cerrados siempre que hablaba, } \\
\text { como si con los ojos se oyera, y } \\
\text { todo el rostro ACABRONADO, quiero } \\
\text { decir, libre, alto y desvengozado. } \\
\text { VICENTE ESPINEL }\end{array}$ \\
\hline $\begin{array}{l}\text { BRONCERÍA. s. f. El conjunto de piezas hechas } \\
\text { de este metal. Aramentum, araria opera. } \\
\text { PALOM. Mus. pict. lib. 2. cap. } 6 \$ 4 \text {. Ya } \\
\text { executamos el edificio, ya las piezas de } \\
\text { platería y broncería. }\end{array}$ & $\begin{array}{l}\text { *BRONCERÍA: f. Arte y oficio del bron- } \\
\text { cista, como se llama platería el arte } \\
\text { y oficio del platero. } \\
\text { [...] ya ejecutamos el edificio, ya } \\
\text { las piezas de platería y BRONCERÍA. } \\
\text { ANTONIO PALOMINO }\end{array}$ \\
\hline $\begin{array}{l}\text { BURGALÉS. s. m. Especie de moneda de baxa } \\
\text { ley, la qual era de oro mezclada de otros } \\
\text { metales, que en tiempo del Rey Don } \\
\text { Alonso el Sabio se mandó usar de ella en } \\
\text { lugar de los Pepiones, moneda de buena } \\
\text { ley. [...] MARIAN. Hist. Esp. lib. 13. cap. } 9 \text {. } \\
\text { Que se usasse de burgaleses, moneda mui } \\
\text { baxa mezclada de otros metales. }\end{array}$ & $\begin{array}{l}\text { BURGALÉS: m. Moneda de oro de muy } \\
\text { baja ley, que valía dos pepiones. } \\
\text { Pareció lo más a propósito que en } \\
\text { lugar de los pepiones, que era cierta } \\
\text { moneda así llamada, de buena ley, } \\
\text { se usase de BURGALESES, moneda } \\
\text { muy baja y de oro mezclado con } \\
\text { otros metales. } \\
\text { MARIANA }\end{array}$ \\
\hline $\begin{array}{l}\text { CARIREDONDO, DA. adj. La persona que tiene } \\
\text { la cara redonda: y por alusión se extiende a } \\
\text { otras cosas que son redondas. Lat. Rotunda } \\
\text { \& orbiculata facie. [...] GónG. Son. var. } 18 . \\
\text { Los más cariredondos girasoles } \\
\text { Imitará siguiéndoos mi albedrío. }\end{array}$ & $\begin{array}{l}\text { *CARIRREDONDO, DA: adj. Por ext. se } \\
\text { dice de lo que tiene forma circular. } \\
\text { Los más CARIRREDONDOS girasoles } \\
\text { imitará, siguiéndoos, mi albedrío. } \\
\text { GóNGORA }\end{array}$ \\
\hline
\end{tabular}




\begin{tabular}{|c|c|}
\hline $\begin{array}{l}\text { CARRETERIL. adj. de una term. Cosa pertene- } \\
\text { ciente a carretas o carros. Lat. Ad plaus- } \\
\text { trum pertinens, tis. BARBAD. Coron. fol. } \\
\text { 103. Era llamada la Reina, por ser la más } \\
\text { rica y la más gorda de todas las Madamas } \\
\text { de aquel mesonage anchuroso y carreteril. }\end{array}$ & $\begin{array}{l}\text { CARRETERIL: adj. Propio de los carre- } \\
\text { teros, o relativo a ellos. } \\
\text { En todos aquellos mesones de } \\
\text { la puerta asoleada era llamada la } \\
\text { reina, por ser la más rica y más } \\
\text { gorda de todas las madamas de } \\
\text { aquel mesonaje anchuroso y } \\
\text { CARRETERIL. } \\
\text { A. DE SALAS BARBADILLO }\end{array}$ \\
\hline $\begin{array}{l}\text { CASERAZO, ZA. adj. aum. de Casero. Lo que es } \\
\text { mui estrecho y familiar. Es voz inventada } \\
\text { y jocosa. Solís, Com. Eurídice y Orpheo. } \\
\text { Jorn. } 2 . \\
\text { Hermano: qué caserazo } \\
\text { requiebro! pero también } \\
\text { se lo llaman los cuñados. }\end{array}$ & $\begin{array}{l}\text { CASERAZO, ZA: adj. aum. de CASERO, RA. } \\
\text { Hermano: iqué CASERAzO } \\
\text { requiebro! Pero también } \\
\text { se lo llaman los cuñados. } \\
\text { Solís }\end{array}$ \\
\hline $\begin{array}{l}\text { EVANGELIZAR. v. a. Anunciar, promulgar, } \\
\text { predicar el Evangelio. Lat. Evangelizare. } \\
\text { Evangelium promulgare, proedicare. [...]. } \\
\text { Nuñ. Empr. } 35 \text {. Especialmente toca al Obis- } \\
\text { po ser Ángel, que con passos de amor dis- } \\
\text { curra, evangelizando paz por su Diócesis. }\end{array}$ & $\begin{array}{l}\text { *EVANGELIZAR: a. Anunciar, promul- } \\
\text { gar felices nuevas. } \\
{[\ldots]} \\
\text { Toca al obispo ser ángel que con } \\
\text { pasos de amor discurra, EVANGE- } \\
\text { LIZANDO paz por su diócesis. } \\
\text { P. FRANCISCO NúÑEz DE CEPEDA }\end{array}$ \\
\hline $\begin{array}{l}\text { FERRADO, DA. part. pass. del verbo Ferrar. } \\
\text { Lo assí guarnecido u señalado con hierro. } \\
\text { Lat. Ferratus. vel Ferro signatus. CERV. } \\
\text { Persil. lib. } 3 \text { cap. } 11 \text {. Que para defender- } \\
\text { nos mui buena torre tenemos, y buenas y } \\
\text { ferradas las puertas de la Iglesia. [...]. }\end{array}$ & $\begin{array}{l}\text { *FERRADO, DA: adj. FÉRREO, RREA. } \\
\text { Entrad, hijos, que para defen- } \\
\text { deros muy buena torre tenemos, } \\
\text { y buenas y FERRADAs las puertas } \\
\text { de la iglesia, que si no es muy de } \\
\text { propósito, no pueden ser derri- } \\
\text { badas ni abrasadas... Auristela y } \\
\text { Constanza pedían a Dios que no } \\
\text { ofendiese el fuego a su templo, } \\
\text { el cual no ardió, no por milagro, } \\
\text { sino porque las puertas era de } \\
\text { hierro. } \\
\text { C...] }\end{array}$ \\
\hline
\end{tabular}


GARABATOSO, SA. adj. Lo que tiene garbo, garabato o atractivo. Es voz voluntaria. Lat. Elegans. Alliciens. Lop. Dorot. f. 38. Miras por lo condolido, con tan garabatosa suavidad que provocas a amor y a lástima.

GARABATOSO, SA: adj. Mal formado, mal hecho.

$$
[\ldots]
$$

- Garabatoso, sa: adj. Garboso, gentil, airoso.

\section{$[\ldots]$}

Porque, fuera del escapulario azul, sobre el hábito blanco, miras, por lo condolido, con tan GARABATOSA suavidad que provocas a amor y a lástima.

LOPE DE VEGA

GRANIZAR. v. a. Arrojar y despedir las nubes granizo.

$$
[\ldots] \text {. }
$$

- GrANIZAR. Metaphóricamente vale arrojar u despedir alguna cosa con ímpetu, menudeando y haciendo que caiga espesso lo que se arroja. Lat. Grandinare. Crepitare. [...]. CERv. Nov. I. pl. 4. Granizaron sobre ella quartos, que la vieja no podía cogerlos.

HOMILISTA. s. m. El escritor de homilías. Es voz de poco uso. Lat. Homilias facies, vel scribens. Hortens. Paneg. pl. 161. Dexo de extender sus significaciones, y referir los elogios, los atributos con que le aclaman Santos y Homilistas.

PLATIFICAR. v. a. Volver o convertir en plata qualquier cosa. Es voz voluntaria. Lat. Argentum efficere. Quev. Fort. Que con solos seiscientos reales había para orecer y platificar todo el Universo mundo.
*GRANIZAR: a. fig. Venir o caer en abundancia sobre uno alguna cosa.

Y así GRANIZARON sobre ella cuartos, que la vieja no se daba manos a cogerlos.

$[\ldots]$

HOMILISTA: m. HOMILIASTA.

Referir los elogios, los atributos, que la aclaman santos y HOMILISTAS.

Fr. Hortensio Paravicino

PLATIFICAR: a. Convertir una cosa en plata.

Con solo seiscientos reales había para orear y PLATIFICAR todo el universo mundo, y que lo más se había de gastar en alambiques y crisoles.

Quevedo 


\begin{tabular}{|c|c|}
\hline $\begin{array}{l}\text { QUINTAR. v. a. Sacar uno de cada cinco, como } \\
\text { le toca la suerte. Usase especialmente en las } \\
\text { reclutas de Soldados, o quando hai que hacer } \\
\text { algún gran castigo en la tropa. Lat. Quintum } \\
\text { quemque sejungere, delegere, capere. [...] } \\
\text { ColmEN. Hist. Segob. cap. } 45 . \text { §. 14. Se infi- } \\
\text { cionó toda España de un catarro contagioso, } \\
\text { que quintó la gente en veinte días. }\end{array}$ & $\begin{array}{l}\text { *QUINTAR: a fig. Causar gran mortan- } \\
\text { dad una epidemia, la guerra, el ham- } \\
\text { bre, etc. } \\
\text { [...] se inficionó toda España de un } \\
\text { catarro contagioso, que QUINTó la } \\
\text { gente en veinte días. } \\
\qquad X^{* * *}\end{array}$ \\
\hline $\begin{array}{l}\text { SAYAZO. s. m. aum. El sayo grande. Lat. Amplus } \\
\text { saccus. QuEv. Tac. cap. Arremangose el } \\
\text { desalmado animero el sayazo, y quedó } \\
\text { con unas piernas zambas en gregüescos } \\
\text { de lienzo. }\end{array}$ & $\begin{array}{l}\text { SAYAZO: } \mathrm{m} \text {. aum. de SAYO. } \\
\text { Hiciéronse la mamona el uno } \\
\text { al otro, arremangose el desalma- } \\
\text { do animero el SAYAZO, y quedó } \\
\text { con unas piernas zambas en gre- } \\
\text { güescos de lienzo. }\end{array}$ \\
\hline & Quevedo \\
\hline
\end{tabular}

Se ha afirmado que los redactores del A2DEHA no contaron con Autoridades como fuente lexicográfica, y no solo porque a partir del cotejo referido se observa paladinamente que, a diferencia de lo que sucedió en el cuerpo del $D E H A$, en esta ocasión no hay una explotación masiva del primer diccionario de la Academia, sino también porque los fragmentos textuales coincidentes no son exactamente los mismos; pareciera que tales coincidencias son simplemente fortuitas, acaso debidas a la lectura y espigueo de las mismas fuentes primarias (§ 3.2). Puede comprobarse que, a excepción de los textos citados en los artículos acabronado y quintar ${ }^{24}$, el fragmento textual citado en el A2DEHA es mayor que el aducido en Autoridades, en ocasiones ciertamente mayor (burgalés ${ }^{25}$, carreteril, ferrado, garabatoso, granizar, platificar y sayazo). Solamente en las entradas evangalizar y homilista es el Diccionario de autoridades el que ofrece un texto ligeramente mayor.

Por otro lado, ha de tenerse en cuenta - y también esto viene confirmar que no se explotó Autoridades como filón textual — que, pese a que algunos textos sean los mismos (con mayor o menor extensión en el A2DEHA), las definiciones son distintas: o bien conceptualmente son diferentes, o bien conceptualmente son semejantes, pero están redactadas de diverso modo. Asimismo, la ausencia de ciertas explicaciones en metalengua de signo o marcas lexicográficas en el A2DEHA sugiere que no se recurrió a Autoridades (cf. artículos acabronado «Es voz voluntaria», caserazo «Es voz inventada y jocosa»,

${ }^{24}$ Sobre la indicación « $\mathrm{X}^{* * *}$ », véase $§ 3.3$.

25 En este caso en particular no solo no coincide la extensión de los fragmentos citados, sino que la obra de Montaner y Simón ofrece un texto que contiene algunas palabras que no se encontraban en el de Autoridades: «moneda mui baxa mezclada de otros metales» (Auts.) y «moneda muy baja y de oro mezclado con otros metales» (A2DEHA). 
garabatoso «Es voz voluntaria», homilista «Es voz de poco uso» o platificar «Es voz voluntaria») ${ }^{26}$.

Otra de las obras a las que podrían haber recurrido los redactores del A2DEHA es el Diccionario de la lengua española (1852) de Adolfo Castro y Rossi, una obra lexicográfica inconclusa, publicada por entregas, que llegó hasta la palabra costra ${ }^{27}$. En este caso es aún más claro que no se tomaron textos de la obra de Castro, pese a que encontremos las dos siguientes coincidencias:

\begin{tabular}{|c|c|}
\hline $\begin{array}{c}\text { Diccionario de la lengua } \\
\text { española (1852) }\end{array}$ & А2DEHA (1907-1910) \\
\hline $\begin{array}{l}\text { AMISTADERO, RA. adj. y también s. m. y f. } \\
\text { La persona fácil en contraer amistades. } \\
\text { Véase la Pícara Justina. }\end{array}$ & $\begin{array}{l}\text { AMISTADERA: adj. Amancebadora. } \\
{[\ldots] \text { la AMISTADERA, la santigua- }} \\
\text { dora y depositaria. } \\
\text { La Pícara Justina }\end{array}$ \\
\hline $\begin{array}{l}\text { CARROZAL. adj. (Ant.) Se aplicaba a lo que } \\
\text { a la carroza pertenece. } \\
\text { «Alborotada la nota carrozal, llegose cerca } \\
\text { de nosotros el autor de la pesadumbre, } \\
\text { muy ufano de lo que había hecho. Díjole } \\
\text { uno de aquellos dos caballeros, Bernado } \\
\text { de Oviedo: si fuera lícito a los hombres } \\
\text { hacer todo lo que pueden, no se fuera } \\
\text { vuestra merced riendo la sinrazón que ha } \\
\text { hecho. Respondió el otro: vuestra mer- } \\
\text { ced no debe saber qué cosa es ser ena- } \\
\text { morado. A lo menos, dijo Bernardo, etc.» } \\
\text { EsPINEL, Escudero Marcos. }\end{array}$ & $\begin{array}{l}\text { CARROZAL: adj. Perteneciente o relativo } \\
\text { a la carrocería. } \\
\text { [...] y se me representó, con la mu- } \\
\text { cha cantidad que había de coches y } \\
\text { carros, una hermosa flota de navíos } \\
\text { de alto bordo... Alborotada la flota } \\
\text { CARROZAL, llegose cerca de noso- } \\
\text { tros el autor de la pesadumbre, } \\
\text { muy ufano de lo que había hecho. } \\
\text { VICENTE ESPINEL }\end{array}$ \\
\hline
\end{tabular}

${ }^{26} \mathrm{Al}$ margen de lo dicho, sabemos que el A2DEHA cita como textos la metalengua de signo empleada por la Academia en las definiciones de sus diccionarios. En la acepción «Piara de ganado mular» del artículo mulada se halla el siguiente texto: «Yegua caponera: La que guía como cabestro la MULADA o caballada cerril, y también las recuas», y tras él, se consigna la referencia «Dic. de la R. A., todas las ediciones». Lo mismo ocurre en el artículo veloncito, donde se cita: «Lámpara de esmaltador: VELONCITO a cuya llama, activada por la acción del soplete, etcétera», en este caso, con la referencia «Dic. de la R. A., 13. edición». La palabra o palabras en cursiva indican el término o la unidad pluriverbal a que corresponde el enunciado definidor académico tomado como autoridad. No existe uniformidad con estas referencias, como se observa en las siguientes: «Dic. de la Academia, 1899» (s. v. collar), «Diccionario de la Real Academia» (s. v. *desemejarse), «Dic. de la Real Academia» (s. v. dínamo), «Dic. de la R. A., 13. edición» (s. v. nervadura), «Dic. de la R. A. y otros, todas las ediciones» (*pasear), etc.

27 A. de Castro y Rossi, Gran diccionario de la lengua española, I [y único: A-costra], Madrid, 1852. Para obtener una visión de conjunto sobre el diccionario de Castro, acúdase a D. Prieto García-Seco, Cuatro siglos de lexicografía española. La recepción de Tirso de Molina en los diccionarios del español, Universidade da Coruña-Servizo de Publicacións, 2014, págs. 62-76. 
Es cierto que estos dos artículos (amistadero/amistadera y carrozal) se construyeron sobre los mismos textos, de La picara Justina (1605) y el Marcos de Obregón (1618) de Vicente Espinel; sin embargo, se observan notables diferencias que no merece la pena comentar (definiciones diferentes, fragmentos textuales de distinta extensión, etc.). Son voces, en fin, cosechadas, junto con sus respectivos textos, a partir de la lectura y espigueo de dichas obras barrocas (§ 3.2).

La siguiente obra lexicográfica sobre la que habría que decir algo es el Diccionario de construcción y régimen (1886-1893) de Rufino José Cuervo. Debemos recordar, en primer lugar, que este diccionario, concretamente el primer volumen, fue una de las obras que proporcionaron textos a los artículos del cuerpo del $D E H A^{28}$. Pues bien, para la elaboración del A2DEHA se volvió a utilizar la obra del bogotano, aunque en escasísimos artículos (cf. abrevar, connaturalizar o desposar).

\begin{tabular}{|c|c|}
\hline DCR (1893) & A2DEHA (1907) \\
\hline $\begin{array}{l}\text { CONNATURALIZAR. V. a) Hacer con- } \\
\text { natural o conforme a la naturaleza } \\
\text { del individuo, hacer propio de ella } \\
\text { (trans.). } \alpha \text { ) Con en, que representa la } \\
\text { persona como campo donde queda la } \\
\text { cualidad o accidente. «De quien [de } \\
\text { la corte] mil veces nos dijo | Tanto } \\
\text { mal --- | Que connaturalizó | En no- } \\
\text { sotros desde niños | Su sabio aborre- } \\
\text { cimiento.» Tirso, Privar contra su } \\
\text { gusto, } 1.12\left(\text { R. } 5.350^{2}\right) .[\ldots]\end{array}$ & $\begin{array}{l}\text { CONNATURALIZAR: a. Hacer connatural. } \| \\
\text { fig. INFUNDIR. } \\
\text { De quien mil veces nos dijo } \\
\text { tanto mal, tantos engaños..., } \\
\text { que CONNATURALIzó } \\
\text { en nosotros desde niños } \\
\text { su sabio aborrecimiento. } \\
\text { TIRSO DE MoLINA }\end{array}$ \\
\hline
\end{tabular}

Sobre las tres obras anteriores hemos pasado de puntillas por los motivos expuestos, que principalmente se reducen a uno, y es que los redactores del A2DEHA no recurrieron a los tres diccionarios mencionados, con la salvedad expresada a propósito del Diccionario de construcción y régimen. En cambio, importa detenerse en tres trabajos lexicográficos a los que sí se prestó atención, puesto que se utilizaron como fuentes secundarias que proporcionaron tanto voces/artículos nuevos como citas textuales.

\subsubsection{Palabras y acepciones castellanas omitidas en el diccionario académico (1906) de José Manuel Aicardo}

El primero de estos tres trabajos son las Palabras y acepciones castellanas omitidas en el diccionario académico (1906) del jesuita José Manuel

${ }^{28}$ Cf. D. Prieto García-Seco, «El Diccionario enciclopédico hispano-americano... (1887-1898)», págs. 108-109. 
Aicardo $^{29}$. Es esta una obra que se inscribe en la lexicografía de los que hemos llamado en otro lugar «rebuscadores de palabras» $»^{30}$. Con esta denominación nos referimos a diversas personas aficionadas a la lexicografía que, durante el primer tercio del siglo XX, se entretuvieron en recopilar a partir de las propias lecturas, normalmente de obras clásicas, voces o acepciones no recogidas en el diccionario usual vigente de la Academia.

El repertorio de Aicardo tiene su origen, según confiesa el autor en la Introducción, en el deseo de dar a conocer las palabras «castizas» de que dispone el castellano con el objeto de evitar lo que considera una invasión de voces del inglés, del alemán y, principalmente, del francés:

Castizo y erudito lector: La pobre lengua castellana está hoy día como ciudad sitiada, como prisionera de guerra cercada de lanzas enemigas [...]. Hostíganla y empújanla a derroteros nuevos, a recibir en su seno cuantos desperdicios echen de sí las demás lenguas, la ignorancia y la audacia de los modernistas, que, sin pararse en barras, forjan palabras, acarrean frases, copian giros franceses, ingleses y alemanes ${ }^{31}$.

También se refiere Aicardo en la Introducción a los «buenos hablistas» cuyas obras ha espigado para cosechar el millar de voces inventariadas.

Su núcleo y parte principal [del repertorio], me parece que su mitad, lo componen vocablos de Lope de Vega, cuya lengua está hoy día tanto o más fresca que la de Quevedo, y mucho más desconocida que la de este, sin duda por la persecución sufrida por Lope, por la raridad de sus ediciones y por lo infinito de su producción, cosas todas que han hecho muy difícil su estudio. ¡Cuánto ganaría el castellano con un Diccionario de Lope de Vega! 32

Tras Lope de Vega, el segundo autor más citado es Cervantes ${ }^{33}$, al que siguen, a gran distancia en lo que se refiere al número de citas aducidas, Pedro Rodríguez Mohedano y Rafael Rodríguez Mohedano (los PP. Mohedanos, Historia literaria de España, 10 ts., 1766-1791), Leandro Fernández de Moratín y José María Gabriel y Galán. En mucho menor medida se toman voces y sus respectivos textos de autores como Quiñones de Benavente [s. v. una (en la) y vedrío], Bretón de los Herreros (s. v. última ratio y vía-crucis) o Pereda (s. v. unción, zonchero y zoncho).

29 J. M. Aicardo, Palabras y acepciones castellanas omitidas en el diccionario académico. Primer millar ordenado por - Establecimiento tipográfico de Fortanet, Madrid, 1906.

${ }^{30}$ Cf. D. Prieto García-Seco, Cuatro siglos de lexicografía española, págs. 118-127.

${ }^{31}$ J. M. Aicardo, op. cit., pág. 5.

32 J. M. Aicardo, loc. cit., pág. 10.

33 «No faltan [en el repertorio], tampoco, un buen centenar de [vocablos empleados por] Cervantes, y solo advierto al lector suspicaz que me he prohibido espigar en el Quijote, por cuanto el presbítero D. Julio Cejador y el profesor de Barcelona D. Clemente Cortejón han tomado sobre sus hombros el vocabulario quijotil» (J. M. Aicardo, loc. cit., págs. 10-11). 
Veamos de qué modo se sirvieron de esta obra en el A2DEHA. Lo primero que ha de decirse es que las Palabras y acepciones castellanas de Aicardo proporcionaron un número importante de voces y sus textos correspondientes; concretamente, en el tramo que estamos estudiando, encontramos setenta y cinco voces, con sendas citas, procedentes de la obra del jesuita ${ }^{34}$, lo que supone, por un lado, un 7,6\% del total de los artículos estudiados y, por otro, el 6,5\% de las citas que contienen tales artículos.

Puesto que, como se ha dicho, la obra de Aicardo concedía una importancia fundamental a Lope de Vega, la mayoría de los textos que el A2DEHA toma del repertorio de Aicardo pertenecen a este autor del Siglo de Oro (cf. baca, badana, bafa, bailadero, bufa, bufonizar, buscayernos, carilamido, etc.), aunque también se tomaron textos de las obras de Martín Laso de Oropesa ${ }^{35}$, Miguel de Cervantes, los PP. Mohedanos, Juan Pablo Forner, Leandro Fernández de Moratín, Luis Montoto o José María Gabriel y Galán.

En general, se toman al pie de la letra los textos que ofrecía Aicardo, aunque cabe encontrar algunas modificaciones. En el artículo miga Aicardo daba el siguiente texto: «La "miga" y la escuela son los primeros establecimientos de enseñanza para los niños del trabajador en Andalucía... Procuraré dar una idea, de la "miga", cuyo nombre no sé yo si será corrupción de amiga o de migaja, que todo pudiera ser»; y el A2DEHA lo acortaba del siguiente modo: «La MIGA y la escuela son los primeros establecimientos de enseñanza para los niños del trabajador en Andalucía».

Estas modificaciones no solo atañen a la extensión del texto, sino a la fonética de algunas voces. En el artículo garlón Aicardo aducía un texto de Gabriel y Galán que decía: «Dici la gente "garlona"...»; el A2DEHA, por su parte, modificó el texto así: «Dice la gente GARLONA...». Se trata de una modificación inadecuada, puesto que el texto de Gabriel y Galán, de su obra Extremeñas, pretendía remedar la fonética particular del castúo, variedad del español de Extremadura. Hay que decir, no obstante, que la alteración fonética del verso de Gabriel y Galán

${ }^{34}$ Compárense en ambas obras los artículos siguientes: baca, bacalario, badana, bafa, bailadero, balaja, bufa, bufonizar, burba, burche, buscayernos, *carear, carilamido, carilindo, carniseco, carpinteril, carux, casilla, casillazo, castrapuercos, chopal, despolvoreo, *desterronar, *desvelar, detonante, enbazamiento, embocada, escriborreteador, *esculteto, *espaldera, evaporado, *garantir, garlón, garrabuño, goticismo, gramatista, granjo, hombriciervo, jumá, *linear, macarelo, *Martín, matamaridos, matatoros, matazorzales, *mico, microcosmía, miente, miga, milenta, *mujer, murrio, muzgo, napel, paramal, *parcial, *parola, partenza, pascualear, pascualiego, plegadura, *poco, poetambre, *quedar, quitatabardillos, robleda, *rollo, ropante, ${ }^{*}$ sor, ${ }^{*}$ sora, tesaurizar, testar, thya, tu y vílica.

${ }^{35}$ Se trata de la obra «Lucano traduzido de verso latino en prosa castellana por Martín Laso de Oropesa, Secretario del Illustríssimo Cardenal don Francisco de Mendoça, Obispo de Burgos», Burgos, 1588. Ha de indicarse que el texto que maneja Aicardo, ed. de 1588, lee: «quando César vio las cohortes enhetradas en tan grande embaçamiento y embaraçadas» (pág. 62); en cambio, el jesuita transcribe: «Cuando vio César las legiones en tan gran embazamiento y embarazadas». Este error de transcripción (legiones por cohortes) pasa al A2DEHA, que copia el texto que le proporciona Aicardo. 
ya se encontraba en las Palabras y acepciones castellanas, puesto que, en realidad, el texto del poeta salmantino era: «Dici la genti galrona» ${ }^{36}$.

Uno de los escollos a los que tuvieron que enfrentarse los redactores del A2DEHA fue la definición de las voces tomadas de las Palabras y acepciones castellanas, dado que Aicardo no suele ofrecer definiciones. Sobre esta notable ausencia nada dice la Introducción a la que nos referíamos más arriba, de manera que no sabemos por qué renunció Aicardo a definir las voces que iba cosechando a partir de sus lecturas. Tras el lema, recogido en negrita y con mayúscula inicial, tan solo se consigna la categoría gramatical del término inventariado, y solo en rarísimas ocasiones se ofrece una suerte de definición en letra cursiva («"Desvelar", v. a. —Despistar.» o «"Devanear", v. n. - Dar vueltas.») ${ }^{37}$. Pues bien, se comprenderá que los redactores del A2DEHA tuvieron que definir de un modo un tanto anómalo las voces que les proporcionó el repertorio de Aicardo, puesto que para ello contaban con una cita - corta en casi todos los casos - en la que aparecía la voz recogida, pero no disponían del contexto, lo que resulta fundamental para un lexicógrafo a la hora de comprender cabalmente el significado de la palabra cuyo concepto se pretende inducir.

Veamos un caso del peligro que se corre al tratar de definir una voz de este modo, casi a ciegas. El repertorio de Aicardo recogía la unidad pluriverbal mujer de punto, avalada con el siguiente texto del P. Ignacio de Camargo: «Liviandades de "mujeres de punto" y muchas veces de princesas $)^{38}$. Al toparse con esta unidad, los redactores del A2DEHA utilizaron la definición sinonímica «RAMERA». Es posible que eligieran esta definición por la presencia de la palabra liviandades en el texto que les proporcionó Aicardo, pero, sobre todo, debieron de sugerir aquella definición otras unidades pluriverbales que contenía el DRAE vigente, el de 1899, como mujer del artelde la vida airadaldel partido/mundana/perdida/pública, que remitían a la voz ramera. Sin embargo, y esto es lo que queremos poner de relieve, si uno lee con detenimiento, y en su contexto, la cita de Camargo - $\mathrm{u}$ otros textos de la época en que ocurra esa unidad- observará que mujer de punto no significa 'ramera', sino 'mujer distinguida y honrada' (en este sentido, nótese que el texto decía «mujeres de punto y muchas veces de princesas», de modo que tanto en un caso como en otro se trata de mujeres distinguidas, de origen noble). En efecto, Cesar Oudin

${ }^{36}$ J. M. Gabriel y Galán, Obras completas, I, Madrid, ${ }^{2} 1912$, pág. 280.

37 En estos casos, en los artículos que presentan una definición, los redactores del A2DEHA obraron de tres modos distintos con la definición que ofrecía Aicardo: aceptándola (cf. garantir «Preservar», partenza «PARTIDA», quitatabardillos «ABANICO», ropante «ROPAVEJERO»), aceptándola, pero completándola (cf. linear «Tachar o borrar con líneas», mico «Turba, copia, multitud», miente «Embustero, mentiroso», testar «Dar testarazos, golpear con la testa») o rechazándola y proponiendo otra definición (cf. espaldera «ESPALDER», murrio «MURRIA», *parcial «CÓMPLICE», poetambre «Multitud de poetas»).

${ }^{38}$ En el mismo artículo de las Palabras y acepciones castellanas se remite a la obra de Emilio Cotarelo Biografía de las controversias sobre la licitud del teatro en España (Madrid, 1904), donde seguramente Aicardo halló el texto citado del también jesuita Camargo. 
definía en su Tesoro de las dos lenguas francesas y española (1607): «Muger de punto, une femme de qualité \& d'honneur» o el Diccionario de autoridades (1737): «Hombre o muger de punto. Se dice de las personas principales y de distinción ${ }^{39}$.

\subsubsection{Palabras, giros y bellezas del lenguaje popular de la Montaña elevado por Pereda a la dignidad del lenguaje clásico español (1907) de Eduardo de Huidobro}

La segunda obra que debemos tratar son las Palabras, giros y bellezas del lenguaje popular de la Montaña elevado por Pereda a la dignidad del lenguaje clásico español (1907) del santanderino Eduardo de Huidobro y Ortiz de la Torre ${ }^{40}$. Este trabajo fue presentado un año antes de publicarse a un certamen literario en honor de José María de Pereda organizado por la Academia de Derecho y Literatura de San Luis Gonzaga, establecida en el Colegio de Estudios Superiores de la Universidad de Deusto. Entre los once temas que proponía la organización del certamen se hallaba precisamente el que da título al trabajo de Huidobro ${ }^{41}$, que finalmente obtuvo el primer premio asignado a dicho tema ${ }^{42}$.

Antes de escribir este trabajo, Huidobro se había interesado por el léxico español en una obra llamada ;Pobre lengua! Catálogo en que se indican más de trescientas voces y locuciones incorrectas hoy comunes en España (1903). Esta obra llegó a alcanzar tres ediciones, cada una de ellas aumentada y, según el autor, mejorada ${ }^{43}$. Por el nombre se inferirá el tenor de la obra. En ella se hace acopio de unidades léxicas que a juicio de Huidobro se empleaban de manera incorrecta. En la entrada balompié, por ejemplo, se afirma:

Me parece muy bien que la Academia no haya aceptado este neologismo propuesto por Mariano de Cavia. Cuando nadie conocía en nuestra tierra

${ }^{39}$ C. Oudin, Tesoro de las dos lenguas francesas y española, París, 1607, s. v. muger de punto; Real Academia Española, op. cit., s. v. punto.

${ }^{40}$ E. de Huidobro, Palabras, giros y bellezas del lenguaje popular de la Montaña elevado por Pereda a la dignidad del lenguaje clásico español, Imp. La Propaganda Católica, Santander, 1907.

${ }^{41}$ Otros temas eran los que siguen: I. La novela en España durante el siglo XIX; II. Juicio crítico general de la obra literaria de Pereda, antes de la publicación de Pedro Sánchez. Análisis de esta obra; III. Juicio crítico general de la obra literaria de Pereda, después de la publicación de Pedro Sánchez. Análisis de Sotileza; IV. Análisis de Peñas Arriba; etc.

${ }^{42}$ E. de Huidobro, Palabras, giros y bellezas del lenguaje popular de la Montaña elevado por Pereda a la dignidad del lenguaje clásico español, pág. 3.

${ }^{43} \mathrm{E}$. de Huidobro, iPobre lengua! Catálogo en que se indican más de cuatrocientas voces y locuciones incorrectas hoy comunes en España (2. ed. «corregida y aumentada», Imprenta de la Propaganda Católica, Santander, 1908, 193 págs.); ;Pobre lengua! Catálogo en que se apuntan y corrigen cerca de seiscientas voces y locuciones incorrectas hoy comunes en España (3. ed. «muy aumentada y mejorada», Imprenta de la Propaganda Católica, Santander, 1915, 275 págs.). 
el terminacho foot-ball, nos divertíamos grandemente los niños del colegio de Orduña y los de otros colegios jugando al balón o al pelotón, que estos dos nombres se dan en Castilla a la pelota de viento; y no teníamos noticia del goal ni del referee ni de otras semejantes bobadas [...]. Dejémonos, pues, de tonterías, y llamemos al foot-ball «juego del pelotón» o «juego del balón» ${ }^{44}$.

Esta obra, manifiestamente purista, además de anglicismos como foot-ball, rechaza numerosos galicismos y en su lugar prescribe la utilización de voces «oriundas» ("“Bisutería." - Viene del francés bijouterie, y es palabra que no ha sido admitida por la Academia. En vez de bisutería debe decirse quincallería, buhonería, etc.»). En su tercera edición recoge un pequeño apéndice, el tercero, dedicado a «algunas voces y acepciones usadas en la Montaña de Santander, que faltan en la última edición del Diccionario» ${ }^{45}$. Tal apéndice se basa en las Palabras, giros y bellezas, en que vamos a centrarnos.

Esta última obra se divide en dos partes: «un vocabulario de voces y frases montañesas usadas por Pereda [págs. 5-122; según el autor "la parte más interesante de esta obrilla", pág. 155], y un florilegio sacado de aquellas de sus obras en que mejor pueden recogerse los giros y bellezas a que se refiere el

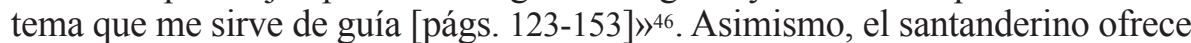
unas «Adiciones» en las que recoge 25 voces más, que justifica del siguiente modo: «Los que echen de menos en él [en el "vocabulario montañés" del cuerpo de la obra] muchos términos comunes en la Montaña y no incluidos en el Diccionario de la Academia adviertan que mi vocabulario es un léxico de Pereda en lo que se refiere al lenguaje popular de la provincia de Santander», y no un «acabado diccionario santanderino» ${ }^{47}$.

El repertorio del «vocabulario montañés» está compuesto por unos 600 artículos. En primer lugar, ha de decirse que no estamos ante un repertorio de gran valor lexicográfico. No contiene indicación de categorías gramaticales ni cualquier otra marca de uso; además, un buen número de las voces recogidas suponen tan solo variantes fonéticas (cancia > hacia; chumpar > chupar; bichorno > bochorno). En cuanto a la información que ofrece cada entrada, es necesario indicar que no es sistemática: unas veces se recoge una definición propia o tomada de otros vocabularios (cf. chumbao, derrota, desborregarse); otras veces se señala a qué voz se corresponde la variante fonética registrada; a veces se avala el término inventariado con fragmentos textuales de distintas obras de Pereda y muchas otras sin texto alguno. Entre otras obras del novelista cántabro, Huidobro manejó las siguientes: Escenas montañesas (1864-1880), Tipos y paisajes (1871), Los hombres de pro (1872), Don Gonzalo

${ }^{44}$ E. de Huidobro, loc. cit., págs. 40-41.

${ }^{45}$ E. de Huidobro, loc. cit., págs. 267-275.

${ }^{46}$ E. de Huidobro, Palabras, giros y bellezas del lenguaje popular de la Montaña elevado por Pereda a la dignidad del lenguaje clásico español, pág. 4.

${ }^{47}$ E. de Huidobro, loc. cit., págs. 155-158. 
González de la Gonzalera (1878), De tal palo tal astilla (1879), El sabor de la tierruca (1881), Pedro Sánchez (1883), Sotileza (1884), La puchera (1889), Pachín González (1895) y Peñas arriba (1895).

Como se ha dicho, en nuestro estudio estamos tomando en consideración los artículos del A2DEHA que contienen citas textuales; sin embargo, conviene señalar que del trabajo de Huidobro no solo se tomaron - lo veremos a continuación - voces avaladas con textos de la obra de Pereda, sino también algunos artículos que carecían de refrendo textual (cf. escajo «Planta silvestre, dura y espinosa», horconada «Golpe con el horcón y porción de heno, paja, etc., que se coje y arroja con el mismo cada vez que se hace uso de él»). En cuanto a los artículos con citas textuales, en los tramos del A2DEHA que estamos analizando hallamos 31 voces y sus respectivos textos tomados de la obra de Huidobro. Solo algunas de tales voces recibieron en el A2DEHA la marca «prov. Sant.», es decir, término provincial de Santander ${ }^{48}$.

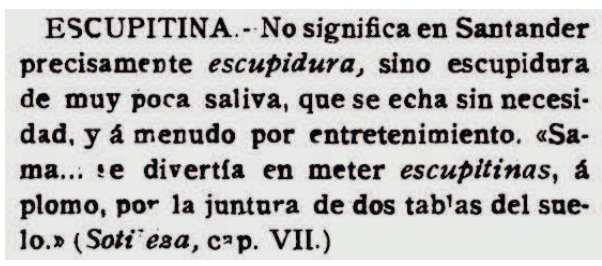

Art. escupitina de Palabras, giros y bellezas... (1907)
* Escupitina: f. Escupidura de muy poca saliva, que se echa sin necesidad, y á menudo por entretenimiento.

Sama... se divertia en meter Escupitrinas, á plomo, por la juntura de dos tablas del suelo.

PEREDA.

Art. *escupitina del A2DEHA (1908)

\subsubsection{Rebusco de voces castizas (1907) de Juan Mir y Noguera}

Al igual que el trabajo de Aicardo, el Rebusco de voces castizas (1907) del jesuita Juan Mir y Noguera se incardina en la lexicografía de los «rebuscadores de palabras ${ }^{49}$. Con su trabajo Mir y Noguera deseaba descubrir, custodiar e incluso difundir, como si de tesoros se tratara, la «gran copia de vocablos» que, habiendo pasado inadvertida para el diccionario usual de la Academia, había permanecido «escondida en las entrañas de las obras clásicas» ${ }^{50}$. La larga «Lista de los autores alegados en este libro» ${ }^{51}$ da cuenta de la cantidad de lecturas que guardaba en su haber el jesuita y, a su vez, pone de relieve la importancia de esta obra, que supera con mucho a las dos anteriores a que nos hemos referido, no solo por su extensión (el Rebusco tiene cerca de 800 páginas), sino por la gran cantidad, y en muchas ocasiones calidad, de la información léxica que se ofrece en torno a las voces recogidas como «artículos» y las incluidas dentro de ellos.

\footnotetext{
${ }^{48}$ Chumpar, daque, juriacán, juriacar, macizo, *macona, marza, parracil (en), pas, quima y rodal.

49 J. Mir y Noguera, Rebusco de voces castizas, Sáenz de Jubera Hermanos, Madrid, 1907.

${ }^{50}$ J. Mir y Noguera, loc. cit., pág. V.

${ }^{51} \mathrm{~J}$. Mir y Noguera, loc. cit., págs. XIII-XXVIII.
} 
La última afirmación nos sugiere que, antes de continuar, dejemos claro que no se trata de un diccionario, pese a que los artículos de la obra se ordenen, como no podía ser de otro modo, según el abecé. Es más bien un repertorio de monografías léxicas encabezadas por una palabra, que normalmente constituye el objeto principal de estudio, pero con frecuencia no supone su único interés. El artículo virotismo, que se reproduce seguidamente, puede ser un buen ejemplo para ilustrar lo que decimos. Como se observa, el sustantivo virotismo motiva la creación de esta monografía, si bien a propósito de él se traen a colación otros términos, como virote, envirotado, etc.

\section{Virotismo}

Al vocablo virote conviénele el sentido figurado de «mozo soltero, ocioso, paseante y preciado de guapo; hombre erguido, demasiadamente serio $y$ quijote». Este sentido nace del virote, que propiamente es especie de saeta, guarnecida con un casquillo". Por ahí podremos rastrear qué será virotismo, y qué significará la frase de la PiCARA Justina: «Dar vado al virotismo» (1).-Dícese virotismo el "andar hecho virote todo el dia» (2), el pasearse holgazán, el gozar de pasatiempos, el seguir la vida poltrona, el darse un verde con dos azules, el andarse á la flor del berro, el holgar y el holgazanear. Bien merecido se tenia lugar en el Diccionario el vocablo virotismo, de tanta aplicación en la vida moderna, si le entendemos conforme queda explicado.

¿Qué será si atendemos á lo tieso y rígido del virote, de cuyas cualidades salió el envirotado metafórico, de que más arriba se trató? Pues asi como envirotado suena entonado, pagado de si, tieso, cuellierguido, lominhiesto, altivo, engreido, presuntuoso; de igual manera al virotismo le corresponde el entono, engreimiento, gravedad, allivez, presunción. Podremos, pues, decir: éste gasta intolerable virotismo; aquél se pierde por su fatuo virotismo; esotro no es hombre de virotismo.

A estos dos diferentes significados se ajusta la palabra virotismo, sin discrepar del dictamen de los clásicos autores.

Art. vitorismo del Rebusco de voces castizas (1907) de Mir y Noguera

La característica más notable del Rebusco radica, sin duda, en que los juicios del autor se amparan en documentación textual, citada, dicho sea de paso, con unas referencias muy precisas, lo que, lamentablemente, no era frecuente en la lexicografía del siglo XIX y principios del XX. En cuanto a las obras que despojó, manejando según confiesa el autor «las primeras ediciones de las obras clásicas $\rangle^{52}$, pertenecen en su gran mayoría a los siglos XVI y XVII, aunque también leyó algunas de otros siglos, como las poesías de Diego de Torres Villarroel (siglo XVIII). Entre otros textos, sobresalen principalmente las voces tomadas de obras del también jesuita Juan de Pineda o de la novela La pícara Justina.

52 J. Mir y Noguera, loc. cit., pág. X. 
El Rebusco posee un interés especial para la historia de la lexicografía española: no solo ejerció una notable influencia en el A2DEHA, sino que otros diccionarios, tanto académicos como extraacadémicos, recurrieron a él para proveerse de voces y, en ocasiones, también de sus textos. En las páginas de la obra de Montaner y Simón que están siendo objeto de nuestro estudio encontramos 114 voces - con sus definiciones y 119 textos correspondientestomadas del Rebusco, lo que supone un 11,5\% de los artículos estudiados (994) y un $10,3 \%$ de los textos contenidos en dichos artículos (1158). Por otro lado, se observa que los redactores del A2DEHA comenzaron a utilizar la información léxica que contenía el Rebusco a partir de la combinación esp-, concretamente a partir de la monografía esperanzoso.

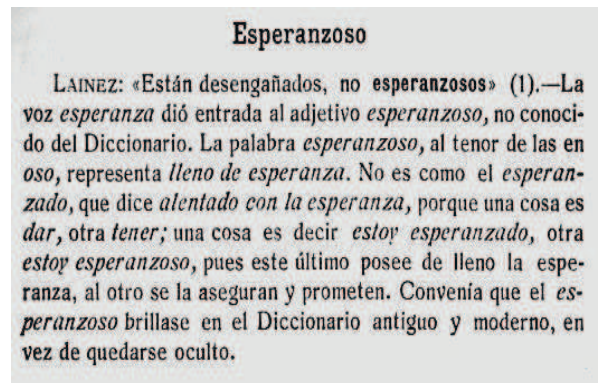

Art. esperanzoso del Rebusco (1907)

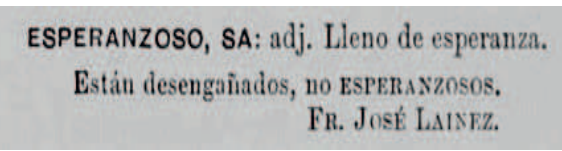

Art. esperanzoso del A2DEHA (1908)

Antes de terminar este apartado, querríamos poner de relieve tres aspectos de la copia del Rebusco. Uno de ellos está relacionado con las autoridades que seleccionó el jesuita para componer su obra. Si bien es cierto que contó con algunos escritores u obras literarias de ficción (Cervantes, Góngora, Lope de Vega, Tirso de Molina, Quevedo, Polo de Medina; La pícara Justina, Estebanillo González, etc.), si uno consulta los artículos de esta obra o acude a la mencionada «Lista de los autores alegados en este libro», observa que abundan los autores religiosos de varias órdenes; por lo tanto, se trata en su mayoría de textos religiosos de diversa índole, como sermones, ceremoniales, homilías, panegíricos de santos, discursos e historias religiosos, etc. A ello se debe la importante presencia de autoridades religiosas en el $A 2 D E H A^{53}$.

${ }_{53}$ Sin pretensión de exhaustividad, pertenece al P. Mir y Noguera la elección de los siguientes autores (autores que figuran también, como queda dicho, en la obra de Montaner y Simón): Sor María de Ágreda, P. Fr. Pedro de Alba, P. Fr. Antonio Álvarez, P. Fr. Juan de los Ángeles, Fr. Diego José Arce, P. Nicolás Arnaya, M. Fr. Alonso de Cabrera, Fr. Juan Francisco de Collantes, P. Fr. Lucas Fernández de Ayala, P. Juan Pablo Fons, P. Fr. Cristóbal de Fonseca, Fr. Juan Gil de Godoy, P. Fr. Antonio Iribarren, P. Juan Antonio Jarque, Fr. José Láinez, Fr. Bernardo de León, P. Fr. Antonio de Lorea, P. Fr. Juan Márquez, P. Fr. Pedro de Mena, P. Fr. Cristóbal Moreno, P. Tomás Muniesa, P. Fr. Diego Murillo, P. Fr. Diego Niseno, P. Francisco Núñez de Cepeda, P. Miguel Ángel Pascual, Fr. Martín Peraza, Fr. Antonio Pérez, P. Fr. Juan de Pineda, P. Fr. Tomás Ramón, P. Fr. Luis de Rebolledo, Fr. Diego Sánchez Maldonado, P. Francisco de 
Por otro lado, llama la atención en el A2DEHA la cita de textos pertenecientes a los dos autores siguientes: Iribarren y Pascual. Cuando uno se topa con estos textos, puede asaltarle la duda de quiénes serán tales autores debido a la lacónica referencia que los acompaña.

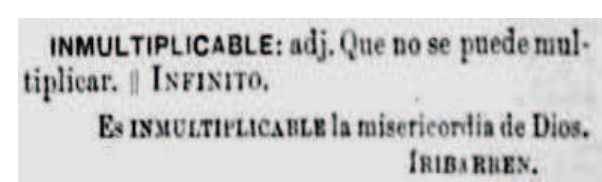

Art. inmultiplicable del A2DEHA (1908)

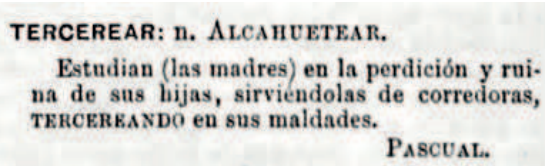

Art. tercerear del A2DEHA (1910)

Si sabemos, como es el caso, que tales textos fueron tomados del Rebusco, se puede acudir a la «Lista de los autores» que proporciona Mir y Noguera al inicio de su obra; sin embargo, en esta ocasión no se halla información al respecto, puesto que ha de tenerse en cuenta que aquella lista no recoge todos los autores que se citan en las monografías de la obra. Hechas las pesquisas correspondientes, en el artículo inmultiplicable Mir y Noguera está citando un texto del dominico Fr. Antonio Iribarren (1655-1710); se trata de una cita a la que recurrirá el autor del Rebusco, a propósito de algunos «adjetivos negativos», en una obra que publicaría un año después, el Prontuario de hispanismo y barbarismo $^{54}$. En dicha obra, en la «Lista de los autores clásicos alegados en este libro», sí se recoge de quién se trata y a qué obra se alude: «Iribarren. — Discurso evangélico, del padre fray Antonio Iribarren, dominico, 1684» ${ }^{55}$.

En el caso del verbo tercerear (y también en el artículo obsecración) se aduce un texto del jesuita Miguel Ángel Pascual (1644-1714). En el Rebusco, en cuya lista tampoco se recoge a este autor, se indica que se está citando un texto de «El oyente, serm. 2, plát. $2 \S 4 »$; sin embargo, poco ayuda esta referencia, puesto que dicho autor publicó varios libros cuyo título principia de tal modo: El oyente desengañado, convencido y remediado (Valencia, Diego de Vega, 1692), El oyente preservado y fortalecido (Valencia, Diego de Vega, 1698) y El oyente remediado por medio del sacramento de la penitencia (Madrid, Diego Martínez Abad, 1698); incluso tenemos una obra llamada El operario instruido y el oyente aprovechado (Madrid, Diego Martínez Abad, 1698).

Finalmente, el tercer aspecto que queríamos poner de relieve es la distinta procedencia de las citas de algunos autores en el A2DEHA. Los redactores de la obra de Montaner y Simón tomaron, como acaba de mostrarse, numerosos textos del Rebusco, textos que pertenecían a autores como Cervantes o Tirso

Santa María, P. M. Fr. Jerónimo de Saona, P. Fr. Juan Suárez de Godoy, P. Juan de Torres, P. Fr. Pedro de Valderrama, P. Fr. Alonso de Vega, P. Fr. Diego de la Vega, Fr. Pedro de Vega, P. Fr. Ignacio de Vitoria y P. Fr. Lorenzo de Zamora. Véase el APÉNDICE que recogemos al final de este trabajo.

54 J. Mir y Noguera, Prontuario de hispanismo y barbarismo, II, Sáenz de Jubera Hermanos, Madrid, 1908, pág. 99.

${ }^{55}$ J. Mir y Noguera, loc. cit., I, pág. CXXXVII. 
de Molina o procedían de obras como La pícara Justina. Pues bien, hay que tener en cuenta que en algunos casos, como sucede con la novela picaresca mencionada, los redactores del A2DEHA también acudieron a los propios textos, a las fuentes primarias, de modo que en este y en otros casos cabe hablar de dos fuentes distintas que proporcionaron textos de una misma obra. En el siguiente apartado nos encargaremos de las fuentes textuales.

\subsection{Fuentes textuales}

Tal y como se ha dicho en la introducción de este trabajo, además de contar con diversos repertorios lexicográficos, el DEHA (1887-1898) acudió a fuentes primarias, a los mismos textos. Pese a que eran conscientes de que la mayor parte de las obras espigadas por el primer diccionario de la Academia pertenecían al Siglo de Oro, los redactores del DEHA, de una parte, volvieron a leer muchas de las obras escrutadas por aquel diccionario dieciochesco y, de otra parte, recurrieron a otras obras, del mismo periodo, no tenidas en cuenta por los primeros académicos. No obstante, dada la fecha de redacción del DEHA, finales del siglo XIX, no cabe duda de que una de sus mayores aportaciones se encuentra en la lectura de textos que, por cuestiones cronológicas, no pudieron tenerse en cuenta para la primera edición de Autoridades, textos de escritores tanto del siglo XVIII como del XIX, si bien resulta especialmente opima la cosecha de textos de autores decimonónicos.

Pues bien, la misma voluntad de despojar fuentes primarias se halla en el A2DEHA, para cuya elaboración se leyeron obras que iban desde la Edad Media hasta fechas inmediatas a la misma confección del diccionario. A tenor de lo dicho, dividiremos las obras manejadas en dos bloques:

A) (i) las obras que fueron tenidas en cuenta en el Diccionario de autoridades $\mathrm{y}$, pese a ello, los redactores del A2DEHA volvieron sobre ellas con el deseo de obtener nuevas voces y acepciones o (ii) las obras que, aunque podrían haberse considerado durante la redacción de Autoridades (desde la Edad Media hasta 1739), no se utilizaron en la redacción de este diccionario de la Academia.

B) las obras que la primera edición del Diccionario de autoridades no llegó a conocer, puesto que se publicaron después de 1739, año del sexto y último volumen de Autoridades.

En cuanto al primer apartado del bloque A, el A2DEHA volvió a espigar obras como el Libro de Alexandre (c1240-1250), La gran conquista de Ultramar (1293) o La pícara Justina (1605). También se acudió nuevamente a diversos autores cuyas obras ya habían sido utilizadas en la elaboración de Autoridades: Pedro Mejía, Miguel de Cervantes, Vicente Espinel, Luis Vélez de Guevara, Pedro Calderón de la Barca, Francisco Antonio Bances Candamo, etc. Un caso 
interesante es el de Sor Juana Inés de la Cruz. Autoridades apenas concedió importancia a su obra, como lo pone de manifiesto el hecho de que tan solo figuren dos textos suyos en el diccionario académico, concretamente en los artículos campo (hacer campo) y salvo. Aunque todavía tímidamente, el A2DEHA comienza la recuperación de sus textos como autoridad léxica, citados, entre otros, en los artículos *balbucencia, cardador, *conchudo, *crecer, *cuaresmar, desencadenador, *fenicio, *gala, magnesio y perfumear.

Un caso semejante al anterior es el de Tirso de Molina, cuyos textos figuran únicamente en ocho artículos de Autoridades ${ }^{56}$. Pensamos que los redactores del A2DEHA debían de ser conscientes de la escasísima fortuna que tuvo Tirso en el primer diccionario académico, puesto que apostaron decididamente por sus obras y a ellas acudieron para despojarlas de todo tipo de voces y acepciones. En un trabajo anterior indicábamos que Tirso de Molina, en este apéndice, se erigió como el segundo autor del Siglo de Otro más citado con respecto a otros escritores consagrados como grandes autoridades léxicas desde los inicios de la lexicografía académica ${ }^{57}$. Téngase en cuenta que el autor áureo al que más se recurre es Lope de Vega, con 576 textos citados en los tres volúmenes del A2DEHA (34,76\%), al que siguen Tirso (437 textos; 26,37 \%), Calderón (327 textos; $19,73 \%$ ), Cervantes (236 textos; $14,24 \%$ ) y Quevedo (81 textos; 4,88 \%). Los datos anteriores se han obtenido a partir de los textos de dichos autores, un total de 1657. Igualmente, puede observarse la importancia concedida a Tirso si tomamos en consideración los tramos del A2DEHA que especialmente están siendo objeto de análisis en este estudio. En tales tramos, como se ha dicho, hallamos 1158 citas textuales, de las cuales 105 pertenecen a Tirso; en consecuencia, las citas del mercedario suponen algo más del $9 \%$, lo que sin duda es un porcentaje altísimo que viene a confirmar la importancia capital que los redactores del A2DEHA otorgaron a las obras del mercedario ${ }^{58}$.

Con respecto al segundo apartado del bloque A, el formado por las obras (o textos) que desechó Autoridades, los redactores del A2DEHA recurrieron, entre otras, a las siguientes: Calila e Dymna (1251), Castigos e documentos del rey don Sancho (1292-1293), Rimado de Palacio (c1385-1407) ${ }^{59}$, El libro de los gatos (c1400?) o el epistolario de Eugenio de Salazar.

Vayamos ya al bloque B. Tal y como hemos adelantado, una de las mayores aportaciones del diccionario que estamos analizando se encuentra en el espigueo

${ }^{56}$ Cf. D. Prieto García-Seco, Cuatro siglos de lexicografía española, págs. 34-35.

${ }^{57}$ D. Prieto García-Seco, «El Diccionario enciclopédico hispano-americano de literatura, ciencias y artes (1887-1910) de Montaner y Simón: primera aproximación», en E. T. Montoro del Arco et alii (coords.), Nuevas perspectivas en torno a la diacronía lingüística. Actas del VI Congreso Nacional de la Asociación de Jóvenes Investigadores de Historiografía e Historia de la Lengua Española (Granada, 29-31 de marzo de 2006), Universidad de Granada, 2008, págs. 430-432 y 435-437.

${ }^{58}$ Sobre la presencia de Tirso en el A2DEHA, pueden obtenerse datos precisos en D. Prieto García-Seco, Cuatro siglos de lexicografía española, págs. 91-97.

${ }^{59}$ De Pero López de Ayala Autoridades había manejado la traducción de la Caída de príncipes, de Giovanni Boccaccio, pero no el Rimado de Palacio. 
de textos de los siglos XVIII, XIX y principios del XX. Al siglo XVIII pertenecen autores como José Francisco Isla, Ramón de la Cruz, Nicolás Fernández de Moratín, Gaspar Melchor de Jovellanos, Juan Meléndez Valdés, Leandro Fernández de Moratín, etc., u obras como La juventud triunfante (1746).

No obstante, como decíamos más arriba, es especialmente abundante la cosecha de textos del siglo XIX. Para ello se acudió a autores como los siguientes: Andrés Bello, Duque de Rivas, Manuel Bretón de los Hereros, Fernán Caballero, Alejandro Oliván, Modesto Lafuente, Juan Eugenio Hartzenbusch, Marino José de Larra, José de Espronceda, Pedro Felipe Monlau, Eugenio de Ochoa, José Zorrilla, Antonio Flores Algovia, Adolfo de Castro, Juan Valera, Emilio Castelar, José María de Pereda, José Castro y Serrano, Juan León Mera, Pedro Antonio de Alarcón, Gustavo Adolfo Bécquer, Urbano González Serrano, Rodrigo Amador de los Ríos, Emilia Pardo Bazán, etc. Debe subrayarse la abundancia de textos tomados de las obras de José María de Pereda y Emilia Pardo Bazán. En los tramos que estamos estudiando encontramos 81 citas del primero y 65 de la segunda (respectivamente, suponen un $7 \%$ y un 5,6 \% de las 1158 citas consideradas). La cifra de 81 textos de Pereda se explica en parte por la explotación de las Palabras, giros y bellezas... (1907) de Eduardo de Huidobro, de la que se tomaron, como queda dicho (§3.1.2), 31 voces y sendos textos.

En tercer lugar, debemos referirnos a los textos manejados del propio siglo XX. En el artículo peormente se cita el siguiente texto de don Emilio Cotarelo y Mori: «Hemos debido hacer una excepción en pro del famoso drama El burlador de Sevilla, tanto por ser la comedia peormente editada por Hartzenbusch, como por la extraordinaria importancia de ella». La cita procede del «Discurso preliminar» que Cotarelo puso al frente del tomo i de las Comedias de Tirso de Molina, publicado en $1906^{60}$.

Veamos otro caso, también relacionado con el dramaturgo anterior. Bajo la voz zurbaranesco se trae a colación el siguiente texto de doña Blanca de los Ríos: "Allí descripciones curiosísimas de los conventos en que vivió Tirso y zurbaranescos retratos de mercenarios maestros y amigos del poeta». Pertenecen estas líneas a la conferencia titulada Tirso de Molina, leída en el Ateneo de Madrid el día 23 de abril de 1906, pero publicada el año 1910 en Del Siglo de $\mathrm{Oro}^{61}$. Nótese, por tanto, el poco tiempo que debió de mediar entre la publicación de dicha conferencia y la papeletización del texto mencionado.

${ }^{60}$ E. Cotarelo y Mori, «Discurso preliminar», en Comedias de Tirso de Molina, I, Bailly-Baillière e Hijos, Madrid, 1906, págs. IV. Este «Discurso» no solo proporcionó al A2DEHA algunos textos de Cotarelo - véase también el artículo *ebonita, con otro fragmento tomado de Cotarelo y Mori (loc. cit., pág. LI) - , sino que de él se cosecharon textos pertenecientes a diversos prólogos de Tirso de Molina y a una dedicatoria suya. Estos textos, aunque fueron tomados de dicho «Discurso», figuran directamente a nombre del mercedario. Al respecto, véase D. Prieto García-Seco, Cuatro siglos de lexicografía española, pág. 93.

${ }^{61}$ B. de los Ríos de Lampérez, Del Siglo de Oro. Estudios literarios, Imprenta de Bernardo Rodríguez, Madrid, 1910, pág. 17. 
Finalmente, debemos subrayar que, en relación con los dos bloques tratados, el A2DEHA recurrió a autores y obras no tenidos en cuenta en el cuerpo de este diccionario enciclopédico. Este debió de ser otro de los nuevos impulsos de su director, Pelayo Vizuete. Al final de este trabajo ofrecemos una tabla en la que se recogen los nombres de los autores y de las obras que figuran en el apéndice estudiado y que no encontramos en el $D E H A^{62}$.

\subsection{Textos sin referencia $\left(\mathrm{X}^{* * * / * * *}\right)$}

Uno de los aspectos que desconciertan al consultante del $A 2 D E H A$ es la cita de textos sin referencia. Aunque no son abundantes, algunos artículos contienen textos que ejemplifican y avalan el uso de un término y, tras tales textos, se consigna una equis seguida de tres asteriscos $\left(\mathrm{x}^{* * *}\right)$. Es el caso de artículos como antitipo, balneoterápico, calcógrafo, carirromo, *centuplicar, ceramógrafo, chacotón, coesencial, coextenso, desbande, *descomponer, desinteresarse, especie, *espontáneo, esquematizar, imaginativamente, internacionalismo, intramercurial, politiquero, protectoramente, *quintar, *remesón, secundador, *triunfo o vitalización.
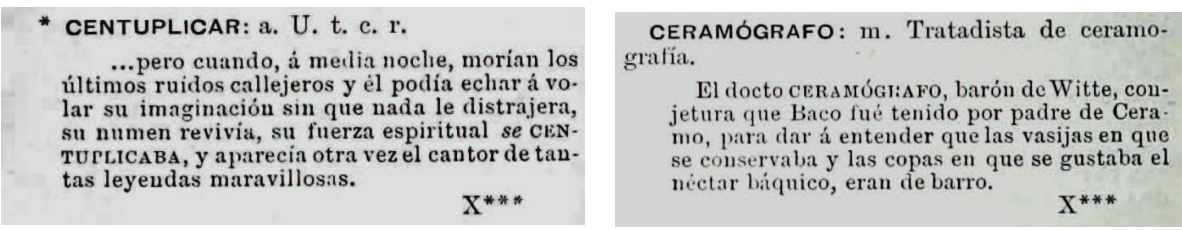

Arts. *entuplicar y ceramógrafo del A2DEHA (1907)

También nos topamos con una variante de aquella indicación en forma de tres asteriscos, sin la equis (altaica, anastomosarse, animalista, caballada, cretinizado o derrumbe). En un primer momento esta falta de referencia podría sugerir que se trata de textos anónimos o quizá de textos inventados ex profeso por los propios redactores, lo que podría servir, con más o menos validez, para ejemplificar el uso de la voz recogida, pero restaría - si no lo anularía - el valor testimonial del texto. Fijémonos en algunos de estos artículos. En la

62 Para la elaboración de esta tabla se ha procedido del siguiente modo. Tras llevar a cabo una nómina con los autores y los títulos de las obras citados en un $10 \%$ del DEHA (1887-1898), porcentaje que se corresponde con las mismas páginas que sirvieron para el cómputo de las citas textuales (al respecto véase la nota 6 de este trabajo; puede consultarse esta nómina en D. Prieto García-Seco, «Las autoridades del Diccionario enciclopédico hispano-americano...», págs. 389-395), hemos recogido en la presente tabla únicamente los autores y las obras mencionados en el $A 2 D E H A$, pero que no aparecían en aquella nómina. El mismo procedimiento se ha seguido con los autores y obras citados en los tramos analizados en este estudio (cf. $\S 3$ ). Téngase en cuenta que reproducimos los nombres de los autores y de las obras tal y como aparecen en el A2DEHA y, solo cuando lo consideramos necesario para la identificación de algún autor, añadimos entre corchetes alguna otra información. 
entrada * caja leemos tras la definición: «Es un infolio de papel grueso distribuido en cuadernillos de seis y ocho hojas de $293 \times 202$ milímetros. La CAJA de imprenta de $229 \times 43$, comprendiendo las cabezas y foliatura». Pues bien, en este caso ni estamos ante un texto anónimo ni ante un ejemplo inventado; se trata de un fragmento de un artículo del jurista vallisoletano Rafael de Ureña y Smenjaud, publicado en la Revista de Archivos, Bibliotecas y Museos ${ }^{63}$.

Otro caso semejante al anterior es el del artículo *quintar, donde se cita un fragmento textual y, tras él, figura la indicación $\left\langle\mathrm{X}^{* * *}\right\rangle$. También es este un texto cuya procedencia podría haberse manifestado, puesto que, como veíamos más arriba (§ 3.1), pertenece a la Historia de la insigne ciudad de Segovia y compendio de las historias de Castilla (1637), del segoviano Diego de Colmenares, texto que ya citaba el Diccionario de autoridades bajo el mismo artículo.

Además de los casos anteriores, en los que se conocía al autor del texto y se decidió omitirlo con la equis y los asteriscos mencionados, observamos que también se emplea la misma indicación con otros fines. En el artículo ceramógrafo, reproducido arriba, leemos: «El docto CERAMÓGRAFO, barón de Witte, conjetura que Baco fue tenido por padre de Ceramo, para dar a entender que las vasijas en que se conservaba y las copas en que se gustaba el néctar báquico eran de barro». Pues bien, en La Ilustración española y americana encontramos el siguiente texto, que presenta un parecido sospechoso con la cita del A2DEHA: «Céramos era hijo de Baco y de Ariadna. Quizá le supusieron los griegos hijo de Baco para dar a entender, como conjeturaba oportunamente el Barón de Witte, que las vasijas en que se conservaba y las copas en que se gustaba el néctar báquico eran de barro» ${ }^{64}$. En este caso, lo que tenemos en el A2DEHA es un texto, que parte en otro, en el que se incluye, con ciertas modificaciones, la voz cuyo artículo les interesaba recoger a los redactores del diccionario. Debe notarse que no se trata de un texto cualquiera, sino de un artículo, del arqueólogo y museógrafo José Ramón Mélida, llamado «Los orígenes del arte cerámico», es decir, un texto en el que, como se verá más abajo, podría haberse empleado perfectamente la palabra ceramógrafo; sin embargo, la realidad es que esta palabra no se encontraba en él y se optó por modificar el texto para que la incluyera. Conviene decir, eso sí, que dicho sustantivo tenía circulación en español desde mediados del siglo XIX: «Entre los ceramógrafos se admiran algunos vasos estruscos y griegos ${ }^{65}$. De hecho, había aparecido en otras ocasiones en diversos artículos de la La Ilustración española y americana, uno de ellos, a propósito, del propio Mélida: «eminentes ceramógrafos contemporáneos,

${ }^{63}$ R. de Ureña y Smenjaud, «Las ediciones de los Fueros y Observancias del Reino de Aragón, anteriores a la compilación ordenada por las Cortes de Monzón de 1547 e impresa en 1552», RABM, IV, no. 4-5, 1900, pág. 220.

${ }^{64}$ La Ilustración española y americana, no XLV, Madrid, 8 de diciembre de 1891, pág. 359 a. [Fundada por el gaditano Abelardo de Carlos y Almansa, aparece su primer número el 25 de diciembre de 1869].

${ }^{65}$ La Revista Universitaria. Periódico científico-literario dedicado a la instrucción pública, Madrid, 23 de agosto de 1856, pág. 11 [comienza a publicarse el 15 de marzo de 1856]. 
como el Barón de Witte, ya citado, y Mr. Dumont»66; «Barón de Witte, cuya exactitud quedará acreditada con decir que es el que en el día aceptan y emplean todos los ceramógrafos. [...] En la isla de Milo se han hallado vasos, decorados, como los precedentes, con figuras de animales, atribuidos por los ceramógrafos a la sétima centuria antes de Jesucristo» 67 ; «notabilísimos ejemplares de barro cocido y vidriado, que justamente han atraído la atención de eruditos ceramógrafos $\rangle^{68}$.

Atendamos a un último texto con la equis y los tres asteriscos, un caso con el que cabe plantear una hipótesis sobre una de las posibles causas que empujaron a los redactores del A2DEHA a silenciar los nombres de los autores cuyos textos citaban. En el artículo escociado se aduce un texto del arabista, historiador y arqueólogo Rodrigo Amador de los Ríos; es un fragmento textual que procede del artículo «Edificios mudéjares olvidados en Toledo», que vio la luz el mes de marzo de 1900 en la Revista de Archivos, Bibliotecas y Museos ${ }^{69}$. Nótese, por tanto, que los redactores del apéndice se sirvieron, como vemos en este caso y en el del artículo *caja, de los trabajos publicados en la afamada Revista de Archivos, Bibliotecas y Museos; sin embargo, en un caso - el de *caja - omitieron, aun conociéndolo, el nombre del autor y en el caso que acabamos de ver - el del adjetivo escociado - no tuvieron problema alguno en nombrar a Amador de los Ríos. No cabe aducir, por tanto, diferencias entre el tipo de trabajo (un artículo científico), el soporte de la publicación (una revista), etc., que expliquen por qué obraron de distinto modo los redactores del A2DEHA. A nuestro juicio, la utilización de la equis y los asteriscos podría deberse al deseo de silenciar a este o a aquel autor por distintos motivos, quizá por desavencecias políticas, culturales, etc.; de otro modo, no se explica que ante casos iguales se procediera, en la referencia de las citas, de manera diversa ${ }^{70}$.

\section{INFLUENCIA DEL A2DEHA EN OBRAS LEXICOGRÁFICAS POSTERIORES}

Si en el apartado 3.1 hemos tratado las obras lexicográficas a las que recurrió el A2DEHA, en este atenderemos a los diccionarios que durante su elaboración acudieron al apéndice que estamos estudiando. Pero antes de referirnos a estos, debemos mencionar, para descartarla, una obra en la que encontramos ciertas coincidencias textuales con el A2DEHA; hablamos del intentado Diccionario

${ }^{66}$ Op. cit., n. XXXI, 22 de agosto de 1882, pág. $103 a$.

${ }^{67}$ Artículo de J. R. Mélida, loc. cit., págs. $106 a$ y $b$.

${ }^{6}$ Loc. cit., n. XI, 22 de marzo de 1885, pág. 178 a.

69 El texto citado en el $A 2 D E H A$ es el siguiente: «La archivolta es de muy menuda labor calada, con una estrecha cinta ESCOCIADA que le encuadraba», tomado de R. Amador de los Ríos, «Edificios mudéjares olvidados en Toledo», RABM, t. IV, 1900, n. 3, pág. 141.

70 En los dos últimos casos comentados ambos autores (José Ramón Mélida y Rodrigo Amador de los Ríos) habían sido redactores del cuerpo del DEHA (§ 1). 
histórico de la lengua española (1933-1936) de la Academia ${ }^{71}$. Estas coincidencias se hallan en las citas aducidas en los siguientes artículos: abortona, acemilado, amistadera, aniel, baloque, buscayernos, cariacuchillado, caribermejo, carihermoso y castañetero. Se trata de textos que pertenecen a Eugenio de Salazar, Lope de Vega, Tirso de Molina, el P. Isla o a obras como La gran conquista de Ultramar y La pícara Justina. Pensamos que tales coincidencias son fortuitas y que se deben a que cada diccionario recurrió por su cuenta a las mismas fuentes primarias. Además de la distinta extensión de los fragmentos citados, creemos que para negar la utilización del A2DEHA en la redacción del Diccionario histórico es más determinante el hecho de que el apéndice ofrezca referencias muy imprecisas, que se limitan a consignar, como sabemos, el nombre del autor o de la obra, mientras que las referencias del Diccionario histórico son mucho más precisas: «Gr. Conq. de Ultr., ed. Riv., t. 44, p. 255» (s. v. aniel) o «La Pícara Justina, ed. Puyol, t. 1, p. 135» (s. v. castañetero). No cabe esperar, por tanto, que los redactores de la obra académica, tras encontrarse con un texto de interés en el A2DEHA, pero sin referencia precisa, se pusieran manos a la obra en la penosa tarea de localizar ese fragmento en una edición de la obra en cuestión ${ }^{72}$.

\subsection{Diccionario de la lengua española (1917) de José Alemany y Bolufer}

Descartado, por tanto, el diccionario anterior, atendamos a aquellos que, con seguridad, se valieron de un modo u otro del apéndice de Montaner y Simón. Una obra donde es patente y notabilísima la influencia del A2DEHA es el Diccionario de la lengua española (1917) dirigido por José Alemany ${ }^{73}$. En un trabajo que dedicamos a este diccionario mostramos de qué manera llegó a adquirir esta obra una de las bondades de que hace gala desde la propia portada: la vastedad del caudad léxico inventariado ${ }^{74}$. En aquel trabajo comprobamos que se había partido como base de la macroestructura y las microestructuras del DRAE de 1914 y, posteriormente, se había aumentado esta base con el material «legado» por distintas fuentes lexicográficas, entre las que se encontraban tanto el cuerpo del DEHA como el A2DEHA. Aunque en algún momento durante la elaboración de la obra de Alemany se pensó en citar la fuente lexicográfica que proporcionara esta voz o aquella acepción, al final se desechó la idea y,

${ }^{71}$ Real Academia Española, Diccionario histórico de la lengua española, Madrid, t. I, 1933 [A] y t. II [B-cevilla].

72 El segundo Diccionario histórico de la Academia (1960-1996: a-apasanca; b-bajoca) utilizó el cuerpo del DEHA como fuente lexicográfica; en cambio, tampoco recurrió al A2DEHA. Explicamos las consecuencias negativas de este hecho en D. Prieto García-Seco, Cuatro siglos de lexicografía española, pág. 187.

73 J. Alemany y Bolufer (dir.), Diccionario de la lengua española, Ramón Sopena, Barcelona, 1917.

${ }^{74}$ Cf. D. Prieto García-Seco, «Notas sobre el Diccionario de la lengua española (1917) de José Alemany», Revista de Lexicografía, XIII, 2007, págs. 125-138. 
en efecto, casi nunca se cita en los artículos la fuente lexicográfica empleada75; sin embargo, en algunos sí se menciona. Por ejemplo, en las entradas siguientes se indica «Según el Dicc. Encicl. Hisp. Amer.»: diantinias, faidas, huachiparis, huamanripa, ibijo, leucanterita, libenerita, magú, mahori, pachana, pachiquil, pachocha o reneta.

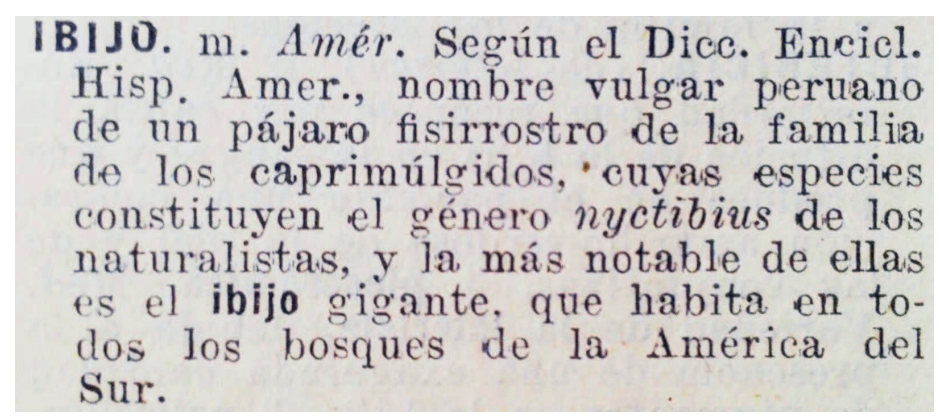

Art. ibijo del Diccionario de la lengua española (1917) de José Alemany

Sin embargo, como decimos, la tónica general es que se calle la fuente lexicográfica manejada. La influencia del A2DEHA es tal que no merece la pena aquí enumerar una larga lista de artículos tomados de la obra de Montaner y Simón. Lo que sí importa decir es que a partir de la comparación de los artículos coincidentes - correspondientes a los tramos que venimos estudiando- se observa que Alemany mantuvo por lo general las definiciones, y otras marcas, tal y como aparecían en el $A 2 D E H A$, pese a que en algunas ocasiones no se trataba de la definición más acertada. Pondremos un ejemplo que consideramos ilustrativo. La definición que da el apéndice de carilamido es la siguiente: «Dícese de la persona que ha sido muy besuqueada»; pues bien, la misma definición, sin el más mínimo retoque, se halla en el diccionario de Alemany por copia del $A 2 D E H A^{76}$.

Ahora bien, no siempre se tomaron las definiciones al pie de la letra; en algunos casos se modificaron, aligerándolas, cambiando algunos términos, añadiendo otros, etc.:

\footnotetext{
75 J. Alemany y Bolufer, op. cit., pág. VI.

${ }^{76}$ Compárense en ambas obras los enunciados definidores de voces como anascotar, azucenal, azufairado, bachilleramente, balconero, baldoque, balneoterápico, caricatural, caricompuesto, cochizarse, * conmílite, conmisionero, cretinizado, churretear (respetamos, como se observa, el orden alfabético de estos diccionarios, que coloca las palabras con $c h$ - después de todas las palabras que comienzan con $c$ - y no según el orden latino internacional, en su lugar correspondiente dentro de la $c$, es decir, después de la combinación ce-), desportilladura, destachonar, desvinculación, dominguerismo, etc.
} 


\begin{tabular}{|c|c|c|}
\hline Entrada & $\begin{array}{c}\text { Definiciones del } A 2 D E H A \\
(1907-1910)\end{array}$ & $\begin{array}{c}\text { Definiciones del } \\
\text { Diccionario de la } \\
\text { lengua española (1917) }\end{array}$ \\
\hline carirromo & $\begin{array}{l}\text { "Que tiene las facciones borrosas, } \\
\text { poco pronunciadas, sin rasgo al- } \\
\text { guno notable». }\end{array}$ & $\begin{array}{l}\text { «Que tiene las faciones pro- } \\
\text { nunciadas». }\end{array}$ \\
\hline caritieso & «De rostro grave y circunspecto». & «De rostro grave y severo». \\
\hline castañetero & $\begin{array}{l}\text { «Que toca las castañetas o cas- } \\
\text { tañuelas. \| Que las fabrica o las } \\
\text { vende». }\end{array}$ & $\begin{array}{l}\text { «Persona que toca las cata- } \\
\text { netas. \| Persona que las fa- } \\
\text { brica o las vende». }\end{array}$ \\
\hline churu & $\begin{array}{l}\text { «Caracol que produce un sonido } \\
\text { ronco y monótono cuando se so- } \\
\text { pla por un orificio que se le abre } \\
\text { en el vértice. Era un instrumento } \\
\text { marcial de los indios, y que toda- } \\
\text { vía utilizan algunos para animar- } \\
\text { se en los trabajos en común». }\end{array}$ & $\begin{array}{l}\text { «Caracol que produce un } \\
\text { sonido ronco y monótono } \\
\text { cuando se sopla por un ori- } \\
\text { ficio que se le abre en el } \\
\text { vértice». }\end{array}$ \\
\hline emboquillado & $\begin{array}{l}\text { «Se dice del cigarrillo que lleva, } \\
\text { en el extremo que se introduce } \\
\text { en la boca, una boquilla hecha de } \\
\text { cartulina o papel fuerte arrollado } \\
\text { en espiral». }\end{array}$ & $\begin{array}{l}\text { «Dícese del cigarrillo que } \\
\text { tiene boquilla de papel fuer- } \\
\text { te en uno de sus extremos». }\end{array}$ \\
\hline espantabobos & $\begin{array}{l}\text { «Persona que infunde pavor a } \\
\text { los ignorantes». }\end{array}$ & $\begin{array}{l}\text { «Persona que infunde pa- } \\
\text { vor a los ignorantes y me- } \\
\text { drosos». }\end{array}$ \\
\hline espantapueblos & $\begin{array}{l}\text { «Dícese de los predicadores que } \\
\text { prefieren las amenazas tremebun- } \\
\text { das a la convicción saludable». }\end{array}$ & $\begin{array}{l}\text { «Dícese de los predicado- } \\
\text { res que prefieren el uso de } \\
\text { las amenazas al de la per- } \\
\text { suasión, en sus sermones». }\end{array}$ \\
\hline
\end{tabular}


Se observan, asimismo, algunos otros cambios en los artículos tomados del A2DEHA, como la adición de información morfológica que el apéndice no ofrecía: caricompuesto «(de cara y compuesto $) »$, conmisionero «(de con y misionero $) »$ o desriñonar «(de des y riñón $) \gg{ }^{77}$.

\subsection{Gran diccionario de la lengua castellana (1902-1931) de Aniceto de Pagés}

Importantísima también es la influencia del A2DEHA en el Gran diccionario de la lengua castellana $\left(1902-1931 ;\right.$ GDLC) de Aniceto de Pagés ${ }^{78}$. Es conocido que gran parte de las autoridades presentes en el cuerpo del DEHA (1887-1898), cosechadas precisamente por Pagés, volvieron a utilizarse en el GDLC. Sin embargo, no sucedió lo mismo con los artículos del A2DEHA y sus textos correspondientes ${ }^{79}$. De acuerdo con los años en que fueron publicándose los cinco volúmenes del GDLC (I, 1902: A-B; II, 1904: C-E; III, c1914: F-M; IV, 1925: N-rho; V, 1931: ría-Z) ${ }^{80}$, podrían haberse tomado los artículos y citas del A2DEHA para el volumen III (1914), es decir, a partir de la F. Sin embargo, no fue así; se explotó este apéndice a partir del artículo parvulista, donde se cita un texto de La Quimera (1905), de doña Emilia Pardo Bazán ${ }^{81}$.

${ }^{77} \mathrm{Si}$ bien no nos detendremos en él, hay que decir que el Diccionario general y técnico hispanoamericano (Madrid, Cultura Hispanoamericana, 1918) de Rodríguez-Navas y Carrasco también copió numerosos artículos del A2DEHA (cf. abarrir, ablucionarse, etc.); se explica, así, que se llegara, si se hizo, a la desmesurada cifra que exhibe la portada: «El presente Diccionario contiene la explicación de 138.762 palabras. El de la Academia Española (14a. edición) da la de 59.235». Tampoco tratamos aquí la influencia de la obra de Montaner y Simón, tanto del cuerpo como del Apéndice segundo, en la Enciclopedia universal ilustrada europeoamericana (1908-1933). Son numerosas las voces que denuncian que esta enciclopedia se sirvió de los materiales léxicos de la de Montaner y Simón (cf. hembrilatina, tutujuleque, etc.).

78 A. de Pagés, Gran diccionario de la lengua castellana, autorizado con ejemplos de buenos escritores antiguos y modernos, Madrid-Barcelona, 1902-1931, 5 vols. [continuado y acabado a partir del vol. IV por José Pérez Hervás].

${ }^{79}$ El trabajo que R. García Cornejo dedica a las fuentes del GDLC no menciona el A2DEHA («Fuentes del Gran diccionario de la lengua castellana de Aniceto de Pagés», en A. Roldán Pérez et alii (eds.), Caminos Actuales de la Historiografía Lingüística. Actas del V Congreso Internacional de la SEHL, I, Universidad de Murcia, 2006, págs. 637-650). Sobre las autoridades del GDLC debe consultarse el extraordinario trabajo de E. J. Jacinto García, El principio de autoridad en los diccionarios generales del español (siglos XVIII-XX), tesis doctoral inédita, dirigida por D. Ignacio Ahumada Lara, leída el 14 de diciembre de 2012 en la Universidad Complutense de Madrid, págs. 483-663.

${ }^{80}$ Según la ficha bibliográfica del GDLC que ofrece la Academia en el Nuevo Tesoro Lexicográfico de la Lengua Española, Espasa-Calpe, Madrid, 2001 [2 DVD].

${ }_{81}$ Compárense en ambos diccionarios los artículos, y sus textos correspondientes, de las voces pas, *pasa, pasamán, pasamuro, pasatarde, pasavolante, pascualear, pascualiego, * pasear, pasera, *pasiego, pasillo, pasionalidad, pasioncica, pasiteo (en el A2DEHA s. v. Pasitea), pasito, pasividad, *pasmar, *persiano, personal, *personarse, picarondonazo, picotico, *pichel, *pierna, piquillo, *pitoflero, pitonicida, pitónico, *planchar, plumajear, pobrón, pontazguear, porquerizo, porredana, portuguesillo, protecturía, rameril, *ramilletero, *regoldar, 


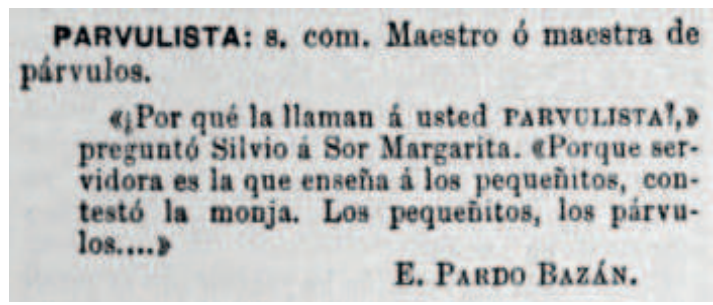

Art. parvulista del A2DEHA (1910)

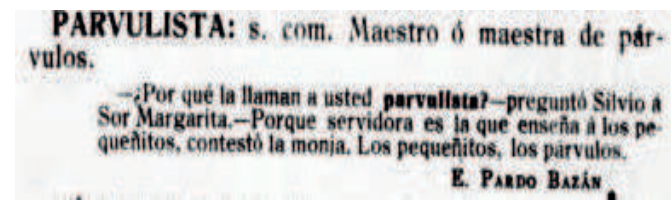

Art. parvulista del GDLC (t. v, 1925)

Prácticamente desde la misma combinación de letras se tomaron las voces, y los textos que las avalaban, del Rebusco de voces castizas (1907) del P. Mir y Noguera (§ 3.1.3). Evidentemente, los artículos copiados tanto del A2DEHA como del Rebusco no pertenecían a Pagés, puesto que había muerto en 1902, sino que fueron despojados de dichas obras lexicográficas por el filólogo valenciano José Pérez Hervás, quien en torno a 1917 se ocupó de continuar la redacción del diccionario del figuerense ${ }^{82}$. Debió de ser tal la labor llevada a cabo por Pérez Hervás que, cuando en 1931 se dio cima al GDLC, algún diario de la época, como mostramos en la siguiente reproducción, llegó incluso a publicitar la obra atribuyéndosela por igual a Pagés y a Pérez Hervás.

requiario, resalgarse, seudocristo, seudoesmeralda, seudofilantrópico, seudomístico, sexenal, solajero, soplonesco, soplonizar, sotasacristán, sotasacristanil, suri, tartarinesco, tercerón, *tijera, titulón, tizama, tomayona, tracedente, tutujuleque, ungüentaria, usasted, *vale, verdegueante, vinarra, vocinglerear, *yema, yepesino, yuncir y zacear.

${ }^{82}$ Cf. D. Prieto García-Seco, Cuatro siglos de lexicografía española, págs. 155-157. 


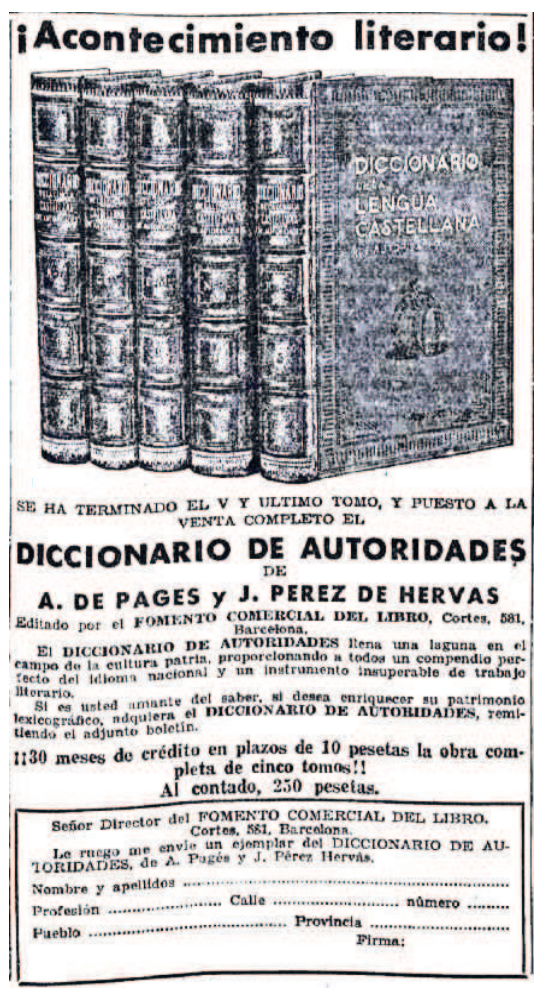

El Sol, 20 de junio de 1931, pág. 2

Pese a que Pérez Hervás aprovechó sistemáticamente las autoridades que le proporcionaba el $A 2 D E H A$, renunció a algunas, por ejemplo, las que se hallaban bajo las voces placentearse, *usurar, vagamundear, xamete, zalomar, zambear o zambullimiento. Por otro lado, se explica en cierto modo que Pérez Hervás descartara los textos con la indicación « $\mathrm{X} * * *$ ( $(3.3)$, dado que, a primera vista, y sin conocer qué se escondía en realidad tras tal indicación, no debían de inspirar mucha confianza unos textos cuya autoría no se manifestaba. Así, dejó de copiar los textos que figuraban en artículos como politiquero, *propulsión, protectoramente, *resabio, solidarista, solidarizar o unicidad. Salvo para las tres últimas voces, Pérez Hervás disponía de uno o varios textos para los demás artículos, lo que explica también que prescindiera de los textos que le ofrecía el A2DEHA. Sin embargo, la ocultación de la autoría no fue óbice para que Pérez Hervás utilizara algunos de tales textos; ante esta situación, en fin, parece ser que pesó más el deseo de autorizar ciertas voces (cf. secundador, signatorio, trallazo, *triunfo, vanidosamente, vitalización o zuequero).

Queremos terminar este apartado dedicado a la influencia del A2DEHA en otras obras llamando la atención sobre un hecho. Seguramente el consultante 
asiduo del Nuevo Tesoro Lexicográfico de la Lengua Española (2001), al realizar ciertas búsquedas, se habrá encontrado con que los únicos diccionarios que recogen algunas voces son precisamente los de Alemany y Pagés ${ }^{83}$. Como fácilmente podrá deducirse a estas alturas, esta coincidencia, que sucede a partir de la combinación pas-, se debe a que ambos diccionarios se nutrieron del A2DEHA, aunque, tal y como se ha mostrado, cada uno lo hiciera de distinto modo.

\section{Conclusiones}

En este estudio hemos intentado poner de manifiesto que la publicación del Apéndice segundo (1907-1910) del Diccionario enciclopédico hispano-americano de Montaner y Simón experimentó un importante cambio de rumbo bajo la dirección de Pelayo Vizuete. Expuestas brevemente las características principales del cuerpo de la obra (1887-1898), nos hemos centrado en las del A2DEHA, mostrando algunos de los grupos léxicos que encontraron una acogida extraordinaria en este apéndice: las voces con marcación técnica o con marcación relativa a diversos ámbitos del conocimiento o de las actividades humanas; las voces con marcación geográfica, con una presencia importante de voces americanas; los gentilicios pertenecientes tanto a grandes como a pequeñas poblaciones, especialmente españolas; o las creaciones léxicas ocasionales, con cuyo registro - como sucedió en el Diccionario de autoridades (1726-1739) o en el Nuevo diccionario (1846) de Vicente Salvá- se daba cuenta de las posibilidades creativas del español.

La parte principal de este trabajo se ha dedicado a las fuentes lexicográficas y textuales empleadas en la elaboración del $A 2 D E H A$, con el objeto de precisar de qué modo establecieron sus redactores el grueso de la macroestructura de este diccionario. Con respecto a los autores y obras citados, debemos subrayar que el A2DEHA llevó a cabo un notable esfuerzo de despojo de fuentes primarias, es decir, se trabajó sobre los propios textos, sobre todo, aunque no únicamente, de los siglos XVIII y XIX. Esta labor inductiva - que es a nuestro juicio la más meritoria - trajo consigo el registro de numerosas voces y acepciones que, además, se avalaron con citas textuales que, como en la mejor lexicografía, cumplían la función de ser garantes y ejemplos de uso.

Sin embargo, no todas las voces o acepciones apoyadas en citas fueron extraídas mediante la lectura y análisis de las obras correspondientes; muchos artículos, junto con sus citas (en torno a un $20 \%$ ), procedían de fuentes lexicográficas que citaban autoridades, como, por ejemplo, el Rebusco de voces castizas de Mir y Noguera. Es importante poner de relieve este hecho por dos motivos fundamentalmente: en primer lugar, para interpretar adecuadamente

${ }^{83}$ Entre muchísimas otras, nos referimos a palabras como pasionidad, pitónico, platonizar, plenciano, protectoramente, protecturía, semicadáver, semiverdadero, seudocristo, signatorio, soflamería, solidarista, trotanubes, volatina, yepesino o zuequero. 
la nómina de autores y textos que ofrecemos al término de este trabajo, puesto que no pueden considerarse en igualdad las obras a las que recurrió el $A 2 D E H A$ (fuentes primarias) y aquellas que fueron manejadas por otros lexicógrafos en sus diccionarios y, posteriormente, el apéndice las hizo suyas (fuentes lexicográficas). En segundo lugar, resulta imprescindible distinguir entre los materiales propios y los ajenos por una cuestión puramente de técnica lexicográfica; hablamos de la falta de homogeneidad en el método de trabajo, que acarrea, inevitablemente, resultados heterogéneos. Evidentemente, no puede ser lo mismo - y, desde luego, no lo es - enfrentarse a la lectura de los textos y a partir de ella cosechar voces y acepciones y posteriormente definirlas que asumir las definiciones dadas por otras obras, o, como hemos visto a propósito de la obra de Aicardo, crear definiciones a partir de pequeños fragmentos textuales, descontextualizados, recogidos en las Palabras y acepciones castellanas.

A tenor de lo expuesto en las líneas precedentes, debemos concluir que el A2DEHA, como toda obra (lexicográfica) de su tiempo, tiene sus virtudes y sus limitaciones, y para valorarlo oportunamente debe ser juzgado dentro de la historia de la lexicografía española. Entre las limitaciones, no cabe duda de que se encuentra la inercia de transitar por los cómodos senderos marcados por la tradición lexicográfica, asumiendo los materiales «legados» por otros diccionarios, aunque a nadie se le oculta que entre estos materiales hubiera, como los hay, algunos de provecho. No obstante lo anterior, con este trabajo también hemos querido subrayar que el A2DEHA posee una gran virtud que lo hace acreedor a un lugar destacado en la historia de la lexicografía de nuestra lengua: haber practicado, aunque parcialmente, la mejor lexicografía, aquella que se sustenta sobre los pilares de los propios textos.

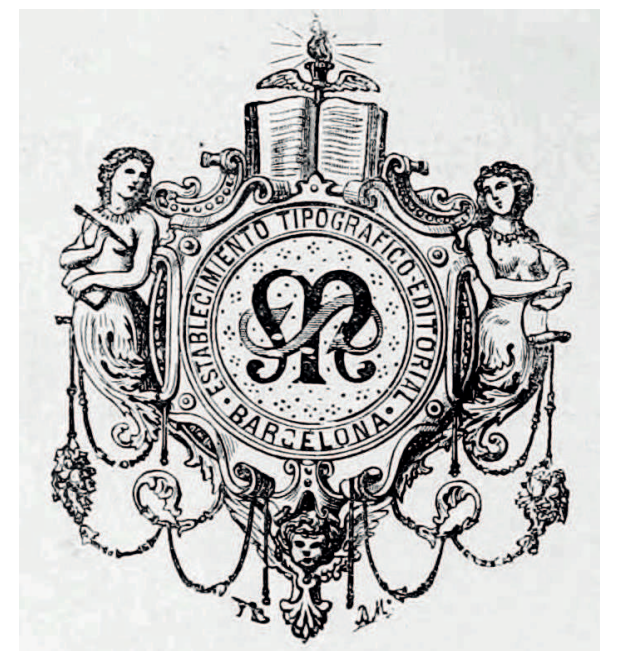

Logotipo del establecimiento tipográfico-editorial Montaner y Simón 
Afán de Ribera, F.

Aguilar y Zúñiga, Esteban de Alarcón, P. Julio

Alba, P. Fr. Pedro de

Alcalá, Dr. Jerónimo de

Aldana, Cosme de

Alvarado, Fr. Francisco

Álvarez, P. Fr. Antonio

Amador de los Ríos, R.

Amunátegui, Miguel Luis

Ángeles, P. Fr. Juan de los

Anónimo

Anónimo del siglo XV

Arce, Fr. Diego José

Arias, P. Francisco

Arnaya, P. Nicolás

Avellaneda, A. F. de

\section{$B$}

Barahona de Soto

Barcia, Roque

Bermúdez de Castro, Diego

Boxadós, Alejo de

Bravo de la Serna, M.

Burgos, P. Juan de

\section{C}

Cabrera, Fr. Alonso de

Calila e Dymna

Calvo, Fernando

Calvo Prieto

Camargo, P. Ignacio de

Camos, Fr. M. Antonio de

Cáncer y Velasco, Juan

Castelar

Castigos e documentos del rey don

Sancho

Cavia, Mariano de
Caviedes, Juan de

Collantes, Fr. Juan Francisco de

Concilio de León

Correas, M. G.

Corrella, P. Fr. Jaime de

Cotarelo y Mori, E.

Cruz, Sor Juana Inés de la

\section{D}

Dicho popular

Durán, Agustín

E

Enríquez de Salas, Diego

Escarias, Pedro de

Espino, Juan del

Esquivel Navarro, Juan de

F

Fernández de Ayala, Fr. Lucas Fernández Medina [Benjamín]

Fernández de Navarrete, E.

Fernández Shaw

Fiameta, siglo XV, La

Fons, P. Juan Pablo

Forner, Juan Pablo

French Matheu, V.

\section{G}

Gabriel y Galán

Gallego, Juan Nicasio

Gallegos, M. de

Garáu, P. Francisco

García, P. Millán

Gayangos, P. de 
Gazulla de Ursino, C.

Gil de Godoy, Fr. Juan

Gilabert, V.

Gómez Manrique

Gómez Ortega

González Serrano, U.

Gracián, P. Baltasar

Gran conquista de Ultramar, La

Guido y Spano, C.

Gutiérrez González

\section{H}

Hernández Blasco, F.

Hogg, Ricardo

Huarte de San Juan, Juan

Huélamo, P. Fr. Melchor de

$$
\text { I }
$$

Iglesia, Antonio de la Iribarren, [P. Fr. Antonio] Isaacs, [Jorge]

Jarque, P. Juan Antonio Jiménez, A. M.

Juan Manuel, Don

Juventud Triunfante, La

$L$

Lafiguera, [Gaspar de la]

Láinez, Fr. José

Lamarque, A.

Larios Medrano

Larramendi, P. Manuel de

Ledesma, Alonso de

León, Fr. Bernardo de

Libro de las consolaciones de la vida humana

Libro de los enxemplos

Libro de los Gatos
López de Arenas, Diego

López Ossorio

López de Yanguas, Hernán

Lorea, P. Fr. Antonio de

M

Maldonado, L.

Malo de Andueza, Fr. Diego

Mansilla, Lucio V.

Martel, Jerónimo

Martínez Zuviría, G. A.

Mélida, José Ramón

Melo

Mena, Fr. Pedro de

Mendo, P. Andrés

Menéndez Pelayo, E.

Mera, [Juan León]

Mir, P.

Mohedanos, PP.

Moncada, P. Jacinto de

Montalvo, Juan

Montoro, A. de

Montoto, L.

Moraes y Vasconcelos, F. B. de

Moreno, P. Fr. Cristóbal

Muniesa, P. Tomás

Murillo, P. Fr. Diego

\section{$N$}

Navarro, Dr. Gaspar

Niseno, P. Fr. Diego

Noticias de Madrid, 1636

\section{$O$}

Obligado, Rafael

Oropesa, Laso de

$$
\text { P }
$$

Palma, Ricardo

Pantaleón y Rivera, A. 
Pascual [P. Miguel Ángel]

Peraza, P. Fr. Martín

Pérez de Hita, Ginés

Pérez de Prado

Pineda, P. Fr. Juan de

Plaza, P. Alonso Luis de

Poema de Alfonso onceno

Ponz, A.

Porres, Dr. Francisco Ignacio de

Pregón popular

\section{$Q$}

Quiroga, A.

Quirós, Pedro de

$$
R
$$

Ramírez y Orta, Dr. Juan

Ramón, Fr. Tomás

Rebolledo, P. Fr. Luis de

Refrán popular

Rimado de Palacio

Ríos de Lampérez, Blanca de los

Roales, Francisco de

Rodríguez, P. Fr. Manuel

Roldán, Belisario

Romancero morisco

Rosell, D. Cayetano

\section{S}

Sal, Juan de la

Salazar, Esteban de

Salazar, Eugenio de

Salvatierra, P. Andrés de

Sánchez, M. Pedro
Sánchez Maldonado, Fr. Diego

Santa María, Fr. Francisco de

Saona, P. M. Fr. Jerónimo de

Sbarbi, José M.

Solís, Fr. Rodrigo de

Soto, P. Fr. Andrés de

Suárez de Godoy, P. Fr. Juan

Suárez y Núñez, M. J.

$T$

Tobar, Carlos R.

Trabalenguas populares

Trad. anón. de Ausias March (siglo XvI)

V

Vaca de Castro, Lic.

Valderrama, P. Fr. Pedro de

Valdivia, Per. de

Valera, L.

Vega, P. Fr. Alonso de

Vega, P. Fr. Diego de la

Vega, Fr. Pedro de

Vegas, Damián de

Viajes de Fray Gerundio [Modesto

Lafuente]

Villalba, Juan Francisco de

Villarroel, Torres

Villegas, P. Bernardino de

Vitoria, P. Fr. Ignacio de

Z

Zamora, P. Fr. Lorenzo de

Zorrilla de San Martín 